\title{
Dualism and cross-country Growth Regressions
}

\section{J onathan T emple and Ludger W ößsmann}

September 2004

\section{Discussion Paper No 04/ 560}

\author{
Department of Economics \\ UNIVERSITY OF BRISTOL \\ 8 WoOdLand Road \\ BRISTOL BS8 1TN \\ UK
}




\title{
Dualism and cross-country growth regressions*
}

\author{
Jonathan Temple ${ }^{\dagger}$ \\ Department of Economics, University of Bristol \\ 8 Woodland Road, Bristol BS8 1TN, UK and CEPR \\ Ludger Wößmann \\ Ifo Institute for Economic Research at the University of Munich \\ Poschingerstr. 5, 81679 Munich, Germany and CESifo
}

September 1, 2004

\begin{abstract}
This paper examines whether growth regressions should incorporate dualism and structural change. If there is a differential across sectors in the marginal product of labour, changes in the structure of employment can raise aggregate total factor productivity. The paper develops empirical growth models that allow for this effect in a more flexible way than previous work. Estimates of the models imply sizeable marginal product differentials, and reveal that the reallocation of labour can explain a significant fraction of the international variation in TFP growth.
\end{abstract}

\footnotetext{
${ }^{*}$ We are grateful to Theo Eicher, Norman Gemmell, Bryan Graham, Stephen Redding, and Peter Temin for helpful contributions. In particular, our study of the disequilibrium case in the paper was prompted by Bryan Graham. We are also grateful to seminar participants at CESifo, the IIES in Stockholm, the LSE, the universities of Bristol, Kent, Leicester, North London, Oxford, Tilburg and Warwick, and the 2004 Econometric Society European Meeting in Madrid. Some of this work was undertaken when Temple visited CESifo in August 2004. He also thanks the Leverhulme Trust for financial support under the Philip Leverhulme Prize Fellowship scheme.

${ }^{\dagger}$ Corresponding author. Email jon.temple@bristol.ac.uk
} 


\section{Introduction}

This paper takes as its starting point three related observations. First, dual economy models have long been an important strand of development economics. Second, development economists in the 1960s and 1970s frequently discussed the role of structural change in economic growth, and especially the reallocation of labour from agriculture. Third, these twin aspects of the development process, dualism and structural change, have been almost completely absent from recent empirical growth research. Much of that research proceeds as if structural change can be ignored. ${ }^{1}$

This paper considers the implications of dualism and structural change for empirical growth models. We study the form of dualism in which the marginal product of labour is lower in agriculture than in the rest of the economy. This differential across sectors could arise for a number of reasons: the costs of ruralurban migration, urban disamenities, a recurring risk of unemployment in urban areas, income sharing in agriculture, or efficiency-wage considerations. It may simply be a disequilibrium phenomenon, associated with technical change or capital accumulation in one sector, and a less than instantaneous migration response.

If the marginal product of labour is relatively low in agriculture, moving workers out of the agricultural sector will raise total output. From the perspective of the aggregate economy, this additional output has been produced with no change in the total inputs of capital and labour. This implies that the reallocation of labour has raised aggregate total factor productivity (TFP). ${ }^{2}$ Our paper seeks to quantify this effect, and examine whether labour reallocation is an important source of TFP growth.

We begin by setting out a simple two sector model of a small open economy. This allows us to examine the conditions under which one sector models, of the type usually adopted in the empirical growth literature, will be good approximations. We also use this model to show how conventional growth regressions can be augmented to allow for structural change. Our regression specification allows the magnitude of the marginal product differential between agriculture and non-agriculture to vary across countries in a more flexible way than previous

\footnotetext{
${ }^{1}$ The textbooks by Bardhan and Udry (1999), Basu (1997) and Ray (1998) include discussions of dualism. Well-known studies of structural change include Chenery and Syrquin (1975) and Chenery et al. (1986). The criticism that too much growth research ignores dualism and structural change has been made by Naqvi (1996), Pack (1992), Ruttan (1998) and Stern (1991) among others. Kelley and Williamson (1973) sounded a much earlier warning that conventional approaches could yield misleading findings in the context of dualism.

${ }^{2}$ Weil (2004, p. 284-289) provides a clear discussion of the aggregate effects of labour misallocation.
} 
work. We use estimates of the model to infer the size and cross-country variation of intersectoral differentials, and compare our results with the available microeconomic evidence.

The precise way we implement the variation in sectoral differentials is new to this paper. We describe a set of assumptions under which the cross-section relationship between growth and the extent of structural change will be convex rather than linear. This result may appear surprising, so we sketch the intuition here. Note that if wages are roughly equal to marginal products, the growth bonus associated with structural change is increasing in the size of the intersectoral wage differential. If we had to guess which countries have the largest wage differential, we might well guess those countries in which the observed extent of structural change is most rapid, reflecting large private gains from switching sectors. Conversely, in countries where structural change has recently slowed down, such as the countries of Western Europe, we might infer that wage differentials have been virtually eliminated. But this implies that the growth impact of a given extent of structural change will be greatest in those countries experiencing more rapid structural change, because these are also the countries, at least on average, in which the intersectoral differential is greatest.

At the aggregate level, this translates into a convex relationship between structural change and growth in the international cross-section, as we describe more formally below. Our estimates of the model suggest this convex relationship may be present in the data, consistent with the idea that marginal product differentials vary systematically across countries. The estimates suggest that, for some countries, the differentials are similar in magnitude to the rural-urban wage gaps observed in microeconomic data (as we discuss further below). Although the empirical estimates are consistent with a significant extent of dualism, we also find evidence that its importance has declined over time.

We use two different approaches to gauge the role of structural change in aggregate TFP growth. One approach is to augment a standard growth regression with structural change terms. The second approach is to use measures of TFP growth taken from previous studies, including Klenow and Rodriguez-Clare (1997) and Bernanke and Gürkaynak (2001). Importantly, we find that regressions including only structural change terms, initial TFP and regional dummies can explain around half the international variation in TFP growth. When the structural change terms are excluded, this proportion falls to a third.

Various objections to this exercise can be raised, and we will discuss many of them later. For those who are inherently sceptical about a cross-country approach, it is worth considering a possible analogy with the empirical literature 
on education and growth. It is well known that studies of this relationship at the aggregate level are faced by serious problems, and that for most purposes it is better to estimate the returns to education more directly, using microeconomic data. On the other hand, it is hard to draw conclusions about the direct impact of education on productivity without estimating production relationships at some level of aggregation (whether firm, industry, region or country).

Similarly, microeconomic observations on rural-urban wage differentials are not directly informative about the extent of differentials in the (unobserved) marginal product of labour. Wages may not be equal to marginal products for a wide variety of reasons, and the microeconomic evidence is potentially misleading in other regards. If we want to investigate the possible extent of marginal product differentials, or quantify the associated effect of structural change on growth, then cross-country growth regressions are worth exploring as a complementary approach. That is the view we have taken in writing this paper.

We should emphasize that the paper does not provide a complete account of the role of structural change, nor does it seek to quantify the overall effect of structural change on growth. Changes in the sectoral allocation of labour allow growth to take place. In their absence, and given that technical change is not uniform across sectors, disequilibrium across sectors would steadily increase, and output would be lower than in the case of smooth adjustment. The present paper does not seek to assess this "permissive" role of structural change in growth, despite its obvious importance. One reason for this omission is that the broader question may not be well posed. Structural change is an endogenous process, driven by sectoral productivity growth, income elasticities of demand, and changes in factor endowments and world prices, among other forces. Given that sectoral structure is clearly a general equilibrium outcome, to ask the question "What is the growth effect of structural change?" may be too much like asking "What is the growth effect of equilibrium prices and quantities?". We therefore restrict attention to a narrower and well-defined question, namely the direct contribution of labour reallocation to aggregate TFP growth in economies that are characterized by sizeable differentials in the marginal product of labour.

The structure of the paper is as follows. Section 2 sketches the basic ideas and relates our work to the existing literature. Section 3 describes an empirical growth model for a small open economy with two sectors. Section 4 presents some stylized facts about dualism and structural change. Sections 5 and 6 , the heart of the paper, report estimates of growth regressions and TFP growth regressions, and robustness tests. Section 7 presents instrumental variable esti- 
mates based on 2SLS, GMM and Fuller's modification of the LIML estimator. Section 8 examines the magnitudes and cross-country variation of the marginal product differentials that are implicit in our empirical results. Finally, section 9 rounds off with a summary and conclusions.

\section{Relation to existing literature}

Our paper is founded on the idea that the marginal product of labour may be higher in urban non-agriculture than in rural agriculture. This idea is linked to a long tradition of dual economy models, including the seminal papers of Lewis (1954) and Harris and Todaro (1970), but we do not address all possible consequences of dualism for the specification of growth regressions. ${ }^{3}$ Instead, we revive a line of empirical research which links dualism, structural change and growth, an area that has been neglected in the burst of empirical studies that followed Barro (1991) and Mankiw, Romer and Weil (1992).

A related strand of research has been to extend growth accounting to incorporate wage differentials. Among the best known contributions is the work by Denison $(1967,1974)$ on the postwar growth of developed countries. Similar ideas also appeared in Kuznets (1961) and are briefly discussed in Barro (1999). The approach is based on including a structural change term, essentially the rate of change of a sectoral employment share, as part of the growth accounting decomposition. The main drawback of Denison's approach and its extension in Temple (2001) is that the magnitude of the intersectoral wage differential is essentially based on an educated guess of one form or another. ${ }^{4}$

The same ideas can be used to derive specifications for cross-country growth regressions, as in a pioneering study by Robinson (1971). In this approach, the researcher treats the structural change term as an explanatory variable, and estimates its coefficient from the data. This removes the need for guesswork about the extent of differentials, at the expense of introducing other problems. Well-known contributions to this line of research include Feder $(1983,1986)$. His specification includes an explanatory variable measuring the rate of change of the labour force in one sector, where the coefficient on this variable is related

\footnotetext{
${ }^{3}$ This means our analysis is closer to models of "modern sector dualism" (or an imperfect labour market) rather than "traditional sector dualism" (where the wage exceeds the marginal product in agriculture, or the agricultural wage is independent of labour demand in the modern sector). This classification of dual economy models is due to Bertrand and Squire (1980).

${ }^{4}$ Related methods for quantifying the effect of resource reallocation have been used by Syrquin $(1984,1986)$ and Pack (1992). Syrquin's method uses data on sectoral outputs and inputs and the capital share to derive what he calls the net allocation effect. The method provides a convenient lower bound on the importance of reallocation, but the required data are not always available for developing countries.
} 
to the intersectoral marginal product differential. Feder's empirical model is derived under restrictive assumptions about the relationship between the marginal products of labour in each sector and economy-wide per capita output, but it is possible to derive a related specification under more general assumptions, as we will demonstrate below.

Recent research on structural change and growth has focused mainly on theory, especially concerning the long-run evolution of sectoral structure. This includes the papers of Atkeson and Kehoe (2000), Bencivenga and Smith (1997), Caselli and Coleman (2001), Echevarria (1997), Galor and Weil (2000), Gollin et al. (2000, 2002), Hansen and Prescott (2002), Kongsamut et al. (2001), Laitner (2000), Lucas (2004), Ngai and Pissarides (2004) and Robertson (1999). Some of these papers have a quantitative component. Caselli and Coleman's (2001) paper examines whether their model can explain features of long-run structural change and convergence across regions of the USA. Echevarria (1997) presents some evidence on changes in sectoral structure, but does not explore the implications of marginal product differentials. Gollin et al. (2000, 2002) investigate the role of agriculture and home production in long-run development, using calibrated models.

The recent papers closest to ours are those of Dowrick and Gemmell (1991), Landon-Lane and Robertson (2003) and Poirson (2000, 2001). ${ }^{5}$ As in our paper, these authors consider the implications of structural change for growth regressions, but we depart from their work in a number of respects. We allow the extent of dualism to vary across countries in a way that is new and potentially appealing. We use estimates of the model to infer not only the magnitude of differentials, but also the extent of their variation across countries. Finally, our main findings are unusually robust, in a variety of dimensions.

Our contribution is more distantly related to a long history of theoretical work on aggregation. The main aggregation result that macroeconomists are familiar with is that, if all firms use the same production technology, face the same factor prices, and use inputs efficiently, then the aggregate production function will just be a scaled-up version of the firm-level production functions. The simplicity of this 'representative firm' approach is appealing, but in a two sector world the task of aggregation is more complicated. This is so even if we assume that capital and labour are homogeneous, and factor returns equalized across sectors. If these inputs are efficiently allocated, to maximize total output, the values of maximized output at given combinations of capital and labour will

\footnotetext{
${ }^{5}$ Another related paper is Paci and Pigliaru (1999). They examine growth in the presence of marginal product differentials, but unlike the present paper, their focus is on convergence across European regions.
} 
trace out a surface that can be thought of as an aggregate production function. ${ }^{6}$ However, this function may not be simple in form. It is easy to show that if two sectors each have Cobb-Douglas production technologies, and if the exponents on inputs differ across sectors, the aggregate production function cannot be Cobb-Douglas. ${ }^{7}$

Since in this paper we assume a marginal product differential between sectors, aggregation is even less straightforward, because the allocation of factors across sectors is no longer efficient. The next section will reaffirm that a two sector economy is unlikely to be well approximated by an aggregate production function, except under restrictive assumptions.

\section{Deriving an empirical growth model}

This section first describes a measure of the extent of structural change, and then develops an empirical model that reveals the connection between aggregate TFP growth and structural change. We also show how growth regressions can be specified to take this effect into account. As discussed in the introduction, our starting point is a simple observation. Countries which exhibit rapid structural change are also likely to be the countries in which the intersectoral wage gap is relatively large. We will show how to make this idea more precise. It leads to a framework for analysing reallocation effects that is more flexible than previous contributions, including those of Feder (1983) and Robinson (1971). It implies an equation for growth that includes two structural change terms: one that captures the growth impact of structural change given an equilibrium wage gap, and one that captures the growth impact of adjustment towards this long-run migration equilibrium.

First of all, in order to develop the idea that the intersectoral wage differential is likely to be highest when the observed pace of structural change is most rapid, we need a measure of the extent of structural change. We adopt the following measure:

$$
p=-\frac{\Delta a}{a}
$$

where $a$ is the share of agricultural employment in total employment. We call this the 'migration propensity', denoted $p$. If we assume that, in the absence of

\footnotetext{
${ }^{6}$ The efficient allocation of factors is crucial here, as pointed out by May (1946) and $\mathrm{Pu}$ (1946). For general treatments of aggregation problems, see Blackorby and Schworm (1988) and Fisher (1992), or Felipe and Fisher (2003) for an accessible review.

${ }^{7}$ The way to see this is to write down the aggregate labour share as a weighted average of labour shares in the two sectors. If the sectoral structure changes, the weights and the aggregate labour share will change, and hence there cannot be an aggregate Cobb-Douglas production function (which would imply a constant labour share at the aggregate level).
} 
migration, the labour forces in the two sectors would grow at the same rate, then the migration propensity can be interpreted as the proportion of agricultural workers who migrate in a given period.

Our empirical framework will assume that the propensity to migrate depends on the ratio of wages in the two sectors. We assume that migration ceases when the intersectoral wage ratio falls to a level denoted by $k$, initially assumed to be the same across countries. Hence in a long-run migration equilibrium, wages in the two sectors ( $w_{a}$ in agriculture and $w_{m}$ in non-agriculture) are related as follows:

$$
w_{m}=k w_{a}
$$

where $k \geq 1 .^{8}$ The equilibrium differential could be thought of as reflecting urban disamenities, or other recurring costs of living in urban areas, such as a perpetual risk of unemployment (Harris and Todaro 1970). Some of our later empirical work will assume that there is no differential in the long-run migration equilibrium (that is, $k=1$ ).

We now require an equation that relates the extent of structural change to the wage ratio. A key assumption is that the strength of this response is roughly the same across countries. Under this assumption, we can use the observed extent of structural change to infer the magnitude of the wage differential, and hence the growth impact of a given employment shift. To implement this empirically, we will restrict attention to models where workers base their migration decisions only on the current ratio of wages in the two sectors. ${ }^{9}$ The particular functional form we choose is:

$$
\begin{aligned}
p & =\frac{x}{1+x} \\
\text { where } x & =\psi\left(\frac{w_{m}}{k w_{a}}-1\right)
\end{aligned}
$$

where the parameter $\psi$ captures the speed of adjustment to the long-run equilibrium, initially assumed to be constant across countries. One possible interpretation of (3) is that it reflects urban job search by agricultural workers, where $p$ is the probability of a successful match with an urban firm, and this match probability is increasing in the intensity of search, which in turn is increasing in the intersectoral wage ratio.

\footnotetext{
${ }^{8}$ We assume that migration only ever takes place in one direction, towards non-agriculture.

${ }^{9}$ This is obviously a simplification, since the migration decision is likely to be forwardlooking. The role of expectations is difficult to capture in a model that can be taken to the cross-country data, however. Our simplification may be reasonable if workers are impatient or adjustment is slow. A similar approach is not uncommon even in theoretical work, as in Neary (1978, p. 674) and Mas-Colell and Razin (1973, p. 75) and the references therein.
} 
Our model does not have explicit microfoundations, but its simplicity allows us to derive a regression specification that is easy to interpret and can be estimated by least squares. We start by using (3) to derive an equation for the modern sector wage in terms of the agricultural wage and $p, k$ and $\psi$. Note that

$$
x=\frac{p}{1-p}=\psi\left(\frac{w_{m}}{k w_{a}}-1\right)
$$

and so we have:

$$
\frac{w_{m}}{w_{a}}=k\left(1+\frac{1}{\psi} \frac{p}{1-p}\right)
$$

where the second term in the bracket is zero in a long-run migration equilibrium (when $p=0$ ). Hence the specification captures the intuition referred to earlier. Under the assumption that the speed of adjustment $(\psi)$ and the equilibrium differential $(k)$ are similar across economies, we can infer the extent of the current wage ratio $\left(w_{m} / w_{a}\right)$ using information on the observed pace of structural change, as measured by $p$.

We now investigate the empirical implications of equation (4). We consider a simple model of a small open economy, essentially a general equilibrium model of production with two sectors and two factors, as in the $2 \times 2$ model of textbook trade theory. The two sectors are rural agriculture and an urban non-agricultural sector, both perfectly competitive. The output of both sectors can be traded on world markets, but the economy is closed to international movements of capital and labour. The agricultural good is the numeraire. Our assumptions imply that world prices tie down the relative price of the modern sector good, and we choose units for this good so that its price can also be normalized to one. Total output is then given by

$$
Y=Y_{a}+Y_{m}
$$

where $Y_{a}$ and $Y_{m}$ are outputs in agriculture and non-agriculture respectively.

Output in each sector is produced by capital and labour. The production functions in the two sectors have constant returns to scale and are given by:

$$
\begin{aligned}
Y_{a} & =A_{a} F\left(K_{a}, L_{a}\right) \\
Y_{m} & =A_{m} G\left(K_{m}, L_{m}\right)
\end{aligned}
$$

where $A_{a}$ and $A_{m}$ are total factor productivity in agriculture and nonagriculture. We assume that workers are paid their marginal products, so we have: 


$$
\begin{aligned}
w_{a} & =A_{a} F_{L} \\
w_{m} & =A_{m} G_{L}
\end{aligned}
$$

where the $L$ subscript denotes the partial derivative with respect to labour. Capital also receives its marginal product in both sectors, and any difference in rental rates is immediately eliminated, so using the same notation we have:

$$
A_{m} G_{K}=A_{a} F_{K}=r
$$

where $r$ is the rental rate on capital (before depreciation). We denote the aggregate labour share by $\eta$ and the capital share by $1-\eta=r K / Y$. It will also be useful to define a variable $\phi=w_{a} L / Y$ which is approximately equal to the labour share. The share of agricultural output in total output is denoted by $s=Y_{a} / Y$.

Our results are extensions to growth accounting decompositions, and these are easiest to develop in continuous time. Growth in aggregate output, using a Divisia quantity index, is equal to:

$$
\frac{\dot{Y}}{Y}=s \frac{\dot{Y}_{a}}{Y_{a}}+(1-s) \frac{\dot{Y}_{m}}{Y_{m}}
$$

The appendix shows that our assumptions lead to an equation for output growth that has the following form:

$$
\frac{\dot{Y}}{Y}=\frac{\dot{Z}}{Z}+(1-\eta) \frac{\dot{K}}{K}+\eta \frac{\dot{L}}{L}
$$

where $\dot{Z} / Z$ is growth in aggregate total factor productivity and is given by:

$$
\frac{\dot{Z}}{Z}=s \frac{\dot{A}_{a}}{A_{a}}+(1-s) \frac{\dot{A}_{m}}{A_{m}}+(k-1) \phi(1-a) \frac{\dot{m}}{m}+k \phi \frac{1}{\psi} \frac{p}{1-p}(1-a) \frac{\dot{m}}{m}
$$

where $m$ is the share of non-agricultural employment in total employment (and hence $m=1-a$ ).

The expression for output growth in (9) should be familiar. It says that, under the current assumptions, output growth can be decomposed into TFP growth and a weighted average of input growth rates, where the weights are equal to the aggregate factor shares. This simplicity is slightly deceptive, however. Given the two sector structure of our model, the aggregate factor shares will tend to vary across countries and over time, even if the sectoral production functions are both Cobb-Douglas. This is because the aggregate factor shares 
will be weighted averages of the sectoral factor shares, with weights equal to the shares of each sector in total value added.

Expression (10), which provides a novel decomposition of aggregate TFP growth, is at the heart of our later empirical work. First of all, consider what happens if there is no wage differential in equilibrium $(k=1)$ and the adjustment response to disequilibrium is instantaneous $(\psi \rightarrow \infty)$. Then TFP growth is simply a weighted average of TFP growth in the two sectors, where the weights are equal to the shares of the sectors in total value added. That is,

$$
\frac{\dot{Z}}{Z}=s \frac{\dot{A}_{a}}{A_{a}}+(1-s) \frac{\dot{A}_{m}}{A_{m}}
$$

This result deserves attention, because empirical growth research has often assumed that TFP growth is the same across countries. One famous contribution is that of Mankiw, Romer and Weil (1992) who justify common TFP growth rates on the grounds that technologies can be transferred across national borders. In a two sector world, this argument no longer goes through, except in unlikely special cases. Aggregate TFP growth is unlikely to be the same across countries even when technology can be costlessly transferred across national borders. ${ }^{10}$

The derivation also reveals the contribution of labour reallocation to TFP growth, in the presence of marginal product differentials. The last two terms of (10) illustrate the 'growth bonus' obtained by reallocating labour to a sector where its marginal product is higher. First of all, consider what happens if the adjustment response to disequilibrium is instantaneous $(\psi \rightarrow \infty)$. Then the fourth term in (10) disappears. As a consequence of instantaneous adjustment, the wage ratio is always equal to $k$, and the third term then captures the TFP effect of labour reallocation for a fixed marginal product ratio. This effect is essentially that examined by Kuznets (1961) and Denison (1967).

If the adjustment response is less than instantaneous, both structural change terms play a role. This is how our empirical model generalizes that of previous work. The migration propensity $p$ is related to the extent of structural change as measured by $\dot{m} / m$, and so equation (10) captures the convex relationship between growth and structural change that was sketched in the introduction to the paper. A major advantage compared to previous work is that the wage differential is allowed to vary across countries with different values of $p$, in the way described by equation (4).

\footnotetext{
${ }^{10}$ In principle one could imagine a long-run equilibrium in which all countries converge to the same sectoral structure. But this, too, is likely to require some restrictive assumptions, and such a long-run outcome is unlikely to be relevant over the time spans considered in our regressions. For relevant empirical work, see Wacziarg (2001) and Imbs and Wacziarg (2003).
} 
In practice the two structural change terms are likely to be highly correlated. Our empirical work will sometimes use restricted models, where we drop one of the two terms and examine the effect of the other. The first option is to assume that adjustment to disequilibrium is instantaneous, so that the disequilibrium term vanishes. The second option is to assume that there is no wage differential in equilibrium, so that $k=1$ and the first structural change term vanishes. We will experiment with both specifications in the empirical work that follows, and show that the disequilibrium term (implying varying differentials) tends to dominate.

In implementing the model described by (9) and (10), we take two approaches. The simplest approach is to estimate equations based on (10) using TFP growth rates previously calculated by Klenow and Rodriguez-Clare (1997), Bernanke and Gürkaynak (2001) and Bosworth and Collins (2003). In this case the regression specification can be thought of as:

$$
\frac{\dot{Z}}{Z}=\omega+(k-1) \phi M G R O W T H+k \phi \frac{1}{\psi} D I S E Q
$$

where the structural change terms (the explanatory variables) are

$$
\begin{aligned}
M G R O W T H & =(1-a) \frac{\dot{m}}{m} \\
D I S E Q & =\frac{p}{1-p}(1-a) \frac{\dot{m}}{m}
\end{aligned}
$$

This specification provides a direct test of whether the structural change terms explain variation in aggregate TFP growth across countries, but involves some approximations. The weighted average of sectoral TFP growth rates indicated by (10) is assumed to be constant across countries. We can relax this assumption by using regional dummies, but this still requires the weighted average to be constant within geographic regions. ${ }^{11} \mathrm{~A}$ second approximation is that, even when the wage ratio is allowed to differ across countries (via $D I S E Q$ ) it must be assumed constant within each country over the time period of the regression. This is reasonable provided that adjustment to the long-run migration equilibrium is slow. In our empirical work, we sometimes look at subperiods, a procedure that allows us to examine whether estimated differentials have changed over time.

The regression (11) is simple and easy to implement. We also use an alternative strategy that has a less direct connection to the theory, but is potentially

\footnotetext{
${ }^{11}$ Based on (10) one solution would be to introduce the output or employment share of agriculture into the regressions, and we experiment with this approach in our later empirical work.
} 
informative. An implication of the two sector model is that cross-country growth regressions should be modified to take into account variation in TFP growth across countries, including the component that is due to structural change in the presence of marginal product differentials. To analyse this in more detail, we take the empirical growth model derived by Mankiw, Romer and Weil (1992) (MRW from now on) and extend it to include structural change terms.

This approach involves some approximations, described in the appendix, but also has a number of strengths. First, unlike measuring TFP growth by accounting methods, it does not require capital stock data. This is a major advantage given that constructing reliable measures of the capital stock for developing countries is a difficult task (Pritchett 2000). Second, we can investigate the extent to which structural change terms raise the explanatory power of some well-known empirical growth models. It turns out that allowing for structural change raises the explanatory power of these regressions substantially. Third, we can also see whether the introduction of structural change terms modifies previous conclusions from growth regressions.

Importantly, many of our findings are independent of whether we use the growth regression approach, or a regression with TFP growth as the dependent variable, as in (11). The one exception to this will arise in the instrumental variable estimates, where (surprisingly) we find it easier to obtain precise estimates of structural change effects when the dependent variable is output growth rather than TFP growth.

Finally, we consider a simple alternative model, in which the structural change terms are constructed slightly differently. We call the model that uses $M G R O W T H$ and DISEQ, Model 1. To be implemented empirically, this model requires that $\phi=w_{a} L / Y$ is approximately constant across countries. We can relax this assumption, at the expense of assuming Cobb-Douglas technology in agriculture. If labour is paid its marginal product, then we have:

$$
w_{a}=\mu \frac{Y_{a}}{L_{a}}=\mu \frac{s Y}{a L}
$$

where $\mu$ is the exponent on labour in the agricultural production function. Hence we have the following relationship:

$$
\phi=\frac{w_{a} L}{Y}=\mu \frac{s}{a}
$$

This suggests using the alternative set of explanatory variables: 


$$
\begin{aligned}
M G R O W T H 2 & =(1-a) \frac{s}{a} \frac{\dot{m}}{m} \\
D I S E Q 2 & =\frac{p}{1-p}(1-a) \frac{s}{a} \frac{\dot{m}}{m}
\end{aligned}
$$

These can be substituted for MGROWTH and DISEQ in the earlier regression specifications, and $\phi$ is replaced by $\mu$ in the corresponding slope coefficients. The assumption that $\phi$ is the same across countries is replaced by an assumption that all countries have the same Cobb-Douglas technologies in agriculture (although TFP levels may differ). When we use MGROWTH2 and DISEQ2, we call this Model 2.

\section{Dualism and structural change: stylized facts}

This section describes the patterns of structural change observed in six regions of the world since 1960. One finding is that structural change has been substantial over the time period usually addressed by growth regressions. We also show that the data are potentially consistent with significant wage differentials across sectors.

Table 1 shows figures for agriculture's share of employment $(a)$ and share of nominal value added $(s)$ for six regions, in 1960, 1980 and 1996. The figures are medians for each region. The data on employment shares are based on the Statistical Database of the Food and Agricultural Organization of the United Nations (FAO 2003). The data on value added shares are taken from the World Bank's (2002) World Development Indicators CD-Rom where available. Where necessary, the WDI data have been supplemented with figures for 1960 taken from the 1990 Production Yearbook of the FAO and the 1987 World Development Report of the World Bank.

Most regions of the developing world have seen a substantial change in sectoral structure over both 1960-80 and 1980-96. This can be measured in terms of an absolute change, or relative to the starting position. Based on the absolute change in the employment share, the shift out of agriculture appears to have been least pronounced in South Asia in 1960-80 and in sub-Saharan Africa in 1980-96. But when looking at the proportionate growth in non-agricultural employment, for 1960-80, this has been greatest in sub-Saharan Africa, rising from $12 \%$ of employment in 1960 to $24 \%$ in 1980 . For 1980-96, it has been greatest in South Asia, rising from $30 \%$ to $40 \%$.

Table 1 also reports a median figure for a measure of relative labour productivity in the two sectors, $R L P$. This is the ratio of the average product of 
labour in the two sectors, as given by

$$
R L P=\frac{Y_{m} / L_{m}}{Y_{a} / L_{a}}=\left(\frac{1-s}{s}\right)\left(\frac{a}{1-a}\right)
$$

Table 1 shows that average labour productivity is substantially higher outside agriculture, a well-known finding that is discussed in Kuznets (1971), Chenery and Syrquin (1975) and Gollin et al. (2000), among others. This should not be used to conclude that agriculture, or factor allocation, is somehow inefficient. Differences in average products will usually be a feature of an efficient allocation, since output is maximized by equating marginal products rather than average products. To illustrate, the simplest way of placing some structure on the relation between the marginal and average products is to assume that technologies in the two sectors are both constant-returns Cobb-Douglas, but with different exponents on capital and labour:

$$
\begin{aligned}
Y_{a} & =A_{a} K_{a}^{\alpha} L_{a}^{1-\alpha} \\
Y_{m} & =A_{m} K_{m}^{\theta} L_{m}^{1-\theta}
\end{aligned}
$$

Then the ratio of marginal value products is given by

$$
\frac{w_{m}}{w_{a}}=\left(\frac{1-\theta}{1-\alpha}\right)\left(\frac{Y_{m} / L_{m}}{Y_{a} / L_{a}}\right)=\left(\frac{1-\theta}{1-\alpha}\right) R L P
$$

If we make the usual (sometimes incorrect) assumption that the non-agricultural sector is more capital-intensive $(\theta>\alpha)$ then it is possible that the marginal products in the two sectors are equal even when $R L P$ is greater than one, as in Table 1. Data on average product differentials cannot establish the existence of dualism, without additional evidence or assumptions. We can be more confident of the following statement, however. If technologies are Cobb-Douglas with parameters that are roughly constant across the world, the rank ordering of marginal product differentials across regions will correspond to the rank ordering of the $R L P$ figures. In other words, if there are significant marginal product differentials, it seems likely that they are greatest in sub-Saharan Africa. This will be taken into account in some of the empirical work that follows.

There are other reasons to be suspicious of the figures on relative productivity (and the data used to construct our structural change terms). It is likely that urban labour is more skilled on average, and that in poorer countries a substantial fraction of agricultural output is unmeasured in the national accounts, as discussed in Parente et al. (2000). Schmitt (1989) points out the dangers of interpreting measures like $R L P$ given that some agricultural labour is allocated 
to non-farm activities. For all these reasons, it seems likely that $R L P$ overstates the relative productivity of workers in non-agriculture.

Another interesting aspect of Table 1 is that, for all regions but South Asia, $R L P$ declines between 1960 and 1996. Based on earlier patterns, Chenery and Syrquin (1975, p. 53) argued that relative productivity in industry and services increases in the early stages of development, before ultimately declining. In contrast, the Table 1 figures suggest that the relative productivity of agriculture improves even at low levels of development. This could be seen as tentative support for the idea that there is a marginal product differential across sectors which is gradually being eliminated over time.

We now consider the pace of structural change in more depth, using the propensity to migrate as defined in equation (1). Table 2 shows the five countries with the most rapid structural change on this measure, and the five slowest. The general pattern is unsurprising: the countries with high probabilities of migration include three that are well-known for fast growth (Japan, Korea and Singapore) while four of the countries with a low propensity for migration are located in sub-Saharan Africa. This calls into question our earlier assumption that the speed of adjustment is similar across countries. Sub-Saharan African countries appear to be characterized by large marginal product differentials and slow rates of migration. Our empirical work will sometimes use a specification in which the structural change terms are interacted with a dummy for sub-Saharan Africa. This allows the equilibrium differential to be greater in Africa and/or the rate of adjustment to be slower.

\section{$5 \quad$ Structural change and growth regressions}

This section and the next, the heart of the paper, will examine whether the reallocation of labour makes an important contribution to growth in aggregate total factor productivity. As discussed previously, our strategy is to introduce structural change terms in otherwise standard cross-country growth regressions, based on the specification of MRW. We also estimate regressions in which measures of TFP growth, as computed by various authors, are used as the dependent variable (section 6). We present results for a variety of specifications, and examine robustness in many dimensions. Our robustness checks include quantile regression and robust estimation, and restriction of the sample to developing countries. Given the possible concern that the extent of structural change will be endogenous in the technical sense (that is, correlated with the disturbances in the regression) section 7 will present estimates from instrumental variable 
procedures.

\subsection{Specification and data}

An issue that deserves special mention is our treatment of human capital in the growth regressions. One of the main criticisms of the original MRW regressions has been their empirical treatment of human capital (see for example Gemmell 1996, Klenow and Rodriguez-Clare 1997 and Pritchett 2001). The human capital measure in MRW is based on the percentage of the working-age population that is in secondary school, obtained by multiplying the secondary enrollment ratio by the fraction of the working-age population that is of school age. Consistent with MRW's theoretical derivation, this can be seen as a flow measure of the rate of investment in human capital.

It may be preferable to attempt direct measurement of the stock of human capital. This can be done using data on average years of schooling in the population aged 15 and older, as constructed by Barro and Lee (2001). The human capital stock data can be integrated into the MRW theoretical framework using equation (12) in MRW (see their p. 418) to derive a growth regression. This approach is straightforward to adopt, the main difference being that it changes the mapping between the slope coefficients and the underlying technology parameters.

Our sample of countries is based on MRW's, which excludes oil producers and those with small populations. In their work, MRW looked at the time period 1960-85. We can now look at a longer time period, 1960-96, using the latest release of the Penn World Table, version 6.1 (Heston et al. 2002). We have chosen 1996 as an endpoint because this maximizes the availability of data for the MRW set of countries. As well as considering 1960-96, we also work with two subperiods, 1960-80 and 1980-96, roughly corresponding to the periods before and after the onset of the debt crisis. Missing values in the Barro and Lee (2001) data set, or sometimes in PWT 6.1, force us to exclude a number of countries from the original MRW sample, so that we are left with a main sample of 76 developed and developing countries.

As a preliminary look at the data, Table 3 reports correlations in the 76 country sample between the MRW variables and five new variables used in this paper. These are MGROWTH and MGROWTH2, as calculated for 1960-96; $D I S E Q$ and $D I S E Q 2$, the migration disequilibrium terms for the same period; and $a_{60}$, the agricultural employment share in $1960 .{ }^{12}$ As one might expect,

\footnotetext{
${ }^{12}$ In constructing the structural change terms, we use the initial employment share $a_{60}$ as the value for $a$ in their theoretical definitions.
} 
MGROWTH and DISEQ are highly correlated, as are MGROWTH2 and DISEQ2.

The first row of Table 3 shows that the correlations of growth $(D Y)$ with the disequilibrium structural change terms (DISEQ and DISEQ2) are noticeably higher than the correlations with the equilibrium structural change terms (MGROWTH and MGROWTH2). This is preliminary support for our new specification, which implies that the cross-section relationship between growth and the extent of structural change should be convex, rather than linear. There is some evidence for this convex relationship in the data, at least when we condition on the other explanatory variables. Figure 1 shows an added-variable (partial scatter) plot of growth over 1960-96, conditional on four explanatory variables (investment, human capital, population growth and initial income) and three regional dummies, against $M G R O W T H$ conditional on the same seven variables. We restrict the sample to 56 developing countries (see below for a definition of this sample and of the regional dummies) but the convexity is equally evident in an added-variable plot for the 76-country sample. The quadratic regression line added to the plot suggests there is some convexity in the growth-structural change relationship: countries with a larger expansion in the employment share of the modern sector do experience a larger growth impact of a given expansion. Our subsequent empirical work will investigate this relationship in more detail. Initially we will focus on the precision of the estimates, before discussing their magnitude in section 8.

\subsection{Initial evidence}

We begin by estimating the standard MRW specification for 1960-85. The dependent variable is the log difference of output between 1960 and 1985, and the explanatory variables are the log of the average investment share, the log of a measure of schooling investment, the log of the average population growth rate plus 0.05, and the log of initial income. For all our OLS regressions, the estimates of standard errors are adjusted for heteroscedasticity using the method of White (1980).

The first results are presented in Table 4. For comparison with the original MRW results, regression (1) shows their model re-estimated using the revised PWT 6.1 data, which excludes 7 of MRW's original sample of 98 countries. The results closely resemble their Table $\mathrm{V}$ findings but with a slightly diminished impact of the investment share and the population growth term. In regression (2), we estimate their model for our main sample of 76 countries, obtaining very similar results. 
We now compare their results to our alternative specification for human capital, supplement the specification with our structural change terms, and extend the period to 1996. First of all, we consider the alternative MRW specification with human capital levels, shown in regression (3). This replaces their human capital measure $(S C H O O L)$ with the logarithm of average years of schooling in the working-age population averaged over the time period. The coefficients are not directly comparable to the MRW specification, but continue to provide support for the effects implied by the augmented Solow model. The estimates imply an output-capital elasticity $(\alpha)$ of 0.55 , an output-human capital elasticity $(\beta)$ of 0.41 , and a convergence rate of 0.012 . These values are of the same order of magnitude as those obtained by MRW (their Table VI) although our estimates of the exponents on inputs $(\alpha$ and $\beta$ ) are higher than in MRW.

Regression (4) supplements the model with the structural change terms, $M G R O W T H$ and DISEQ calculated for 1960-85. They are not individually significant, but the disequilibrium term $D I S E Q$ is approaching significance at the $10 \%$ level and there is strong evidence of joint significance, as revealed by the corresponding Wald test (F-statistic 28.59; p-value 0.00). Hence the MRW specification is firmly rejected in favour of the more general specification that we adopt. Moreover, the inclusion of the structural change terms raises the explanatory power of the growth regression to an unusual extent. The $R^{2}$ rises from 0.43 to 0.59 .

We now move to a longer time period, 1960-96, shown in regression (5). The results are similar. The parameter values implicit in the coefficient estimates, after adjusting for the altered length of the time period, are largely unchanged. $D I S E Q$ is again approaching significance, and the two structural change terms are jointly significant at the $1 \%$ level (F-statistic 13.24; p-value 0.00). We also consider whether the structural change terms are significant when entered separately. Our derivation of the empirical model described assumptions under which one term, either MGROWTH or DISEQ, can be dropped. We refer to these as restricted models, and report the associated results as regressions (6) and (7). In either case, the single structural change term is significant at the $1 \%$ level. The model based on DISEQ has slightly greater explanatory power.

Finally, regressions (8) and (9) are based on two subperiods, 1960-80 and 1980-96. In both subperiods, the two structural change terms are positively signed and jointly significant, although only at the $7 \%$ level in the later subperiod. In the two restricted models (not shown) each individual term is significant in both subperiods. In the later subperiod (1980-96) the magnitude of the coefficient estimates and their precision is reduced, and the structural change terms 
add less to the explanatory power of the MRW model. One possible explanation is that the extent of dualism declined over the course of the 1980s and early 1990s.

\subsection{Further evidence}

We now consider further evidence, presented in Table 5. The time period is 1960-96 throughout. All the regressions from this point onwards include four regional dummies, corresponding to sub-Saharan Africa, non-OECD East Asia and the Pacific, Latin America and the Caribbean, and the high-income OECD countries, using the World Bank (2002) classifications. The coefficients on the regional dummies are not reported.

Regressions (10)-(12) in Table 5 show that our earlier findings are robust to the inclusion of regional dummies. The structural change terms are jointly significant (regression 10) or individually significant in the restricted models (regressions 11 and 12). MGROWTH is negatively signed in regression 10, but the estimates are imprecise given the use of both structural change terms. The disequilibrium term DISEQ dominates in this specification, and is significant even when both structural change terms are included.

In regression (13), we add the initial share of employment in agriculture (a60) as an explanatory variable. This allows us to check that the structural change terms are not simply a proxy for initial specialization in agriculture, which could affect growth for a wide variety of reasons. ${ }^{13}$ As shown in regression (13), allowing for this effect does not change the results. The new variable is not significant at conventional levels and the structural change terms remain jointly significant (F-statistic 14.8; p-value 0.00). Furthermore, in the two restricted models (not shown) the initial agricultural employment share is again insignificant at conventional levels, while each structural change term remains significant.

In section 3, we also derived an alternative specification for the structural change terms, which we called Model 2. In regressions (14)-(16) we show that our findings are robust to this alternative specification, even though we now have fewer observations (due to lack of the required additional data on agriculture's share of value added). MGROWTH2 and DISEQ2 are jointly significant (Fstatistic 10.0, p-value 0.00) and are significant when entered separately. The same findings hold for the two subperiods (results not shown).

What can we conclude thus far? There is clear evidence for structural change

\footnotetext{
${ }^{13}$ An alternative approach would be to add the output share as an explanatory variable. We prefer to use the employment share because it is available for a larger number of countries.
} 
effects associated with marginal product differentials. The two structural change terms almost always have the predicted signs, are jointly significant, and greatly increase the explanatory power of otherwise standard growth regressions. The disequilibrium term DISEQ performs especially well, and this supports our case for allowing the cross-section relationship between growth and structural change to be nonlinear (remember this can arise if the marginal product differential varies across countries). There is also some evidence that the extent of dualism, as reflected in marginal product differentials, has declined over time. We will explore this further in section 8.

\subsection{Robust and quantile regressions}

We now perform several further robustness checks, mainly to ensure that our results are not driven by outlying observations. The message of these tests is that our results are unusually robust. The results are contained in Table A1 in the appendix, and the discussion that follows could be skipped by readers more interested in our overall conclusions than in the details of robustness tests.

First, we estimate the regressions with the median regression estimator (MR), also known as the LAD estimator. This estimator minimizes the sum of the absolute residuals, and is therefore less sensitive to outliers than an estimator like OLS that minimizes the sum of squares. ${ }^{14}$ The results can be found in Appendix Table A1, as regressions (A1)-(A6). Our findings are robust to the use of median regression.

Second, we also implement an alternative robust regression technique that drops or downweights outliers. The method we use starts by eliminating gross outliers for which Cook's distance measure is greater than one, and then iteratively downweights observations with large absolute residuals. ${ }^{15}$ Inspection of the ensuing weights reveals that in both possible specifications, the Democratic Republic of Congo (formerly Zaire) and Botswana are assigned a zero weight. These are the two countries in our sample with the lowest and highest growth rates over 1960-96. Countries that also receive weights of less than 0.5 (compared to a possible maximum of 1) are the Philippines, Nicaragua, Mauritius, and Zambia. Our results are essentially unchanged on downweighting these observations (see regressions A7 and A8).

We have also estimated regressions that exclude Singapore (see regression

\footnotetext{
${ }^{14}$ In particular, the MR estimator may be preferable to least squares when the distribution of the regression errors has thick tails. If the errors are i.i.d. with a Laplace distribution, and distributed independently of the explanatory variables, then the MR estimate of a linear model is also the maximum likelihood estimate.

${ }^{15}$ This estimator corresponds to the rreg robust estimation command in Stata.
} 
A9). This country combines fast growth with by far the highest value of the propensity for migration (as listed in Table 2). This is likely to reflect a very small agricultural sector, given that Singapore is a city-state. The OLS, MR and $\mathrm{RR}$ results are all robust to the exclusion of Singapore. One difference is that the disequilibrium term is no longer individually significant in the unrestricted model containing both terms. Nevertheless, the structural change terms retain joint significance at the $1 \%$ level.

Overall, we conclude that our results are not driven by the presence of outliers. We now consider whether the effects of structural change vary across regression quantiles. ${ }^{16}$ Figure 2 plots the 19 quantile regression estimates for each 0.05 percentile interval for the two restricted models. For either structural change term, the estimated effect is surprisingly uniform across the full range of quantiles of the conditional growth distribution, and usually lies within the confidence interval of the OLS estimate (the exception here is the 90th percentile estimate for DISEQ $).{ }^{17}$ The interpretation of this result depends on the sources of the disturbances, but our quantile regression estimates do rule out certain systematic forms of parameter heterogeneity.

\subsection{Structural change in developing countries}

Our empirical work thus far has used a large sample of countries, developed and developing, with very different sectoral structures and patterns of structural change. We now examine whether the structural change effects can be identified even in a sample restricted to developing countries. To achieve this, we exclude the 20 countries in our main sample that are classified as high-income OECD countries in World Bank (2002). This set of high-income countries is broadly the same as the group of OECD members in the late 1960s, and hence excluding them should leave us with a sample that corresponds reasonably well to those countries considered less developed in the 1960s. The final three columns in Table 5 are based on this restricted sample, and regressions (17)-(19) show that our previous findings apply even when developed countries are excluded.

We also consider robustness issues for this sample (56 countries for Model 1 and 48 countries for Model 2). The results are shown in Appendix Table A2. The results are qualitatively the same as before, and again can be skipped by readers more interested in the overall findings. The point estimates of the coefficient on the disequilibrium term are slightly larger in the developing country sample.

\footnotetext{
${ }^{16}$ See Koenker and Hallock (2001) for an introduction to quantile regression.

${ }^{17}$ Note that in a sample of this size, there is likely to be considerable uncertainty associated with estimating the relationship that holds at the extremes of the conditional distribution.
} 
We find essentially the same results as before when using Model 2, including the initial agricultural employment share, or examining the two subperiods (results not reported).

Earlier in the paper, we noted the possibility of slower adjustment in subSaharan Africa. We have estimated regressions which include interaction terms, in which MGROWTH and DISEQ are interacted with the Africa dummy. These interaction terms are statistically insignificant, even jointly. The disequilibrium term DISEQ remains significant (regression A13). These results are tentative evidence that a simple model may capture the growth effects of structural change adequately even for sub-Saharan Africa.

We have also carried out some robustness tests for the developing country sample, based on MR estimation. The two structural change terms are jointly significant only at the $13 \%$ level, but this weaker result seems to be driven by the presence of Singapore. In the two restricted models, the structural change terms are significant regardless of whether or not Singapore is included. In further results, not reported, we have confirmed that our findings are not sensitive to outliers and the use of robust estimation. This includes the results for the Model 2 specification based on MGROWTH2 and DISEQ2. Also as found previously, the quantile regression estimates are remarkably uniform throughout the conditional growth distribution. In this developing country sample, the estimated effects of $M G R O W T H$ for the lowest three 5\%-percentiles fall below the confidence interval of the OLS results, but all DISEQ estimates fall within the OLS confidence interval. Again, this provides some support for our regression specification.

\section{Structural change and TFP growth}

Thus far, our examination of structural change and growth has been based on cross-section growth regressions, with all their attendant econometric problems. Some of the problems, such as the possible endogeneity of the investment variable, may cause the impact of structural change to be understated. Nevertheless, it is also possible that the regressions overstate the extent of structural change effects.

We now consider regressions in which the dependent variable is a measure of TFP growth constructed by previous researchers, using growth accounting. We have used three measures: primarily estimates of TFP growth rates over 1960-85 due to Klenow and Rodriguez-Clare (1997), but also estimates for 196595 due to Bernanke and Gürkaynak (2001) and for 1960-2000 due to Bosworth 
and Collins (2003). ${ }^{18}$ In principle, we should measure TFP growth for each country using country-specific factor shares, but these are hard to measure for developing countries, especially given problems raised by self-employment and unincorporated enterprise (Gollin 2002). For this reason, we use TFP growth rates that assume common factor shares across countries. ${ }^{19}$

The sample is again based on the non-oil set of countries used by MRW, but limited by data availability. Note that the coefficient estimates will not be directly comparable with earlier results. This is because the growth regressions are based (as in MRW) on the log difference of GDP per worker over the respective periods, whereas the TFP growth regressions use the annual growth rate of TFP measured in percentage terms. All our TFP regressions include the same set of regional dummies used previously. Since TFP growth is likely to reflect, at least in part, a process of technological catch-up, we have included the log of initial TFP as an additional control variable whenever it can be constructed from the available data.

We begin with the Klenow and Rodriguez-Clare measure (KR). The Table 6 results for the KR measure, regressions (20)-(25), tell a story very similar to that of the previous regressions. In the unrestricted model for the full sample, reported as regression (20), the two structural change terms MGROWTH and $D I S E Q$ are jointly significant (F-statistic 19.61, p-value 0.00). When entered separately, as in the restricted models shown in regressions (21) and (22), each term is positive and significant at the $1 \%$ level. Results for the Model 2 specification, based on MGROWTH2 and DISEQ2, are very similar, as can be seen from regressions (23)-(25). Once again the two structural change terms are jointly significant. Also note that these models can account for around half the international variation in TFP growth. For comparison, when the structural change terms are dropped the $R^{2}$ falls to 0.33 .

When the initial agricultural employment share is included as an additional control variable, it is rarely significant in these TFP growth regressions, and it never changes the results on the structural change terms. Our findings continue to be robust to the use of MR and robust regression, and to the exclusion of Singapore. Results are similar when the sample of countries is restricted to the developing country sample (as in regressions A21 and A22 in Appendix Table A3). As before, the results are robust to including interactions of the structural change terms with a dummy for sub-Saharan Africa.

\footnotetext{
${ }^{18}$ We are grateful to these authors for making their calculations of TFP growth available.

${ }^{19}$ Bernanke and Gürkaynak (2001) calculate alternative TFP growth estimates using data on country-specific factor shares, but for a much smaller sample of countries. Our results are robust to using these alternative data (not shown).
} 
We now consider alternative measures of TFP growth. Bernanke and Gürkaynak (2001) provide a range of TFP growth measures for 1965-95. We focus on the series which assumes a labour share of 0.65 and an annual return to additional years of schooling of $7 \%$. We construct structural change terms for 1965-95, but the FAO (2003) data on employment shares are available only for 1960 and 1970. We approximate the 1965 value by a mean of the two. The levels of statistical significance are slightly lower when using this TFP growth measure (regressions 26-28) but the general pattern of results is not greatly different from previous findings. When using the Bosworth and Collins measure for 1960-2000, the results are weaker, but Model 2 has some explanatory power (regression 29). Note that we cannot control for the initial level of TFP in these regressions because Bosworth and Collins construct their TFP series using national prices.

Overall our results are consistent with the hypothesis that the reallocation of labour, in the presence of marginal product differentials, makes a sizeable contribution to aggregate TFP growth. Our relatively simple models explain a significant fraction of the observed variation in TFP growth, and therefore help to chip away at this 'measure of our ignorance'.

\section{Instrumental variable estimates}

Structural change is clearly an endogenous process, driven by a variety of economic forces. Whenever the relationship between TFP growth and structural change is estimated from the data, a major concern is that the extent of structural change may be endogenous also in the technical sense, namely correlated with the regression disturbances. Informally, one might expect the coeffcients on structural change terms to be biased away from zero. The magnitude of this effect is an open question, but here we attempt to address the problem using instrumental variable methods, including 2SLS, GMM and Fuller's (1977) modification of the LIML estimator. The motivation for using Fuller's estimator is the possible weakness of our instruments, something that we discuss further below.

In the present context, the main candidates for instruments will be variables that affect either the potential supply of migrants, or the incentives to migrate, or both. Our primary instrument is POPAGE, the share of the population aged between 0 and 14 in 1960, since the young are particularly likely to have strong incentives to migrate. Over the course of our time period, those aged between 0 and 14 in 1960 will have reached the 15-30 age group among which migration tends to be concentrated (Mazumdar 1987, p. 1119). We also use the log of 
relative labour productivity, $L R L P$, at the beginning of the period, since the incentives to migrate may be correlated with the observed extent of dualism. Relative labour productivity is constructed as in section 4 .

Although both these instruments have some appeal, it would be easy to criticise the associated exclusion restrictions. We also experiment with an alternative strategy, which is to estimate growth regressions for 1980-96 and include lagged structural change terms (1960-80) among the instruments. When using any of these approaches, estimating the full model with both structural change terms is ambitious. It requires us to find an instrument set such that the fitted values of the endogenous explanatory variables are not highly correlated, and this is difficult to achieve in practice. For this reason, we focus on restricted models (just one structural change term) throughout.

All our IV models contain regional dummies and the MRW regressors, but we only report the coefficient and standard error on the structural change term, for ease of comparison across the different estimation methods, including OLS for comparison. ${ }^{20}$ We first consider estimates of model 1 for 1960-96, as regressions (30) and (31) in Table 7. In this first case, the proposed instrument LRLP60 has little explanatory power for structural change, and we drop it from the instrument set. Since the model is then exactly identified, 2SLS and GMM give the same point estimates, but the standard errors in the GMM results are heteroskedasticity-robust. The coefficients on either structural change term, $M G R O W T H$ or DISEQ, are significantly different from zero at the $5 \%$ level.

Based on the 2SLS results, we implement a Wu-Hausman test. This does not reject the exogeneity of the structural change terms at conventional levels, but comes close to doing so (p-value of 0.29 for MGROWTH and 0.20 for DISEQ). It is important to note, however, that this near-rejection does not arise because the 2SLS estimates of the structural change parameters are closer to zero than before (the expected pattern). Instead, the 2SLS coefficients are larger than the OLS estimates, although they also have high standard errors. This suggests either mis-specification of the system, or measurement error in the structural change terms that causes the OLS results to be biased towards zero.

In general, when estimating the models using IV methods, we find stronger results for Model 2. Estimates of this model for 1960-96 are presented as regressions (32) and (33) in Table 7. Again, the Wu-Hausman tests come close to rejecting exogeneity, but the 2SLS coefficients on the structural change terms are again larger than the OLS estimates. In these models, LRLP60 has some

\footnotetext{
${ }^{20}$ To implement the different estimators, we use the latest version of the ivreg2 software for Stata. See Baum et al. (2003).
} 
explanatory power for structural change, and we can therefore test overidentifying restrictions. These restrictions are not rejected by a Sargan test (for 2SLS) or Hansen's J-test (for GMM).

Finally, we consider estimates of Model 2 for the 1980-96 period (model 1 works much less well). Here we instrument using POPAGE and the lagged value of the structural change term, calculated over 1960-80. In these estimates, the structural change terms are not significant at conventional levels when using 2SLS and Fuller's estimator, but are significant at 10\% in the GMM estimates and $15 \%$ in the others. Again we find no evidence to reject the validity of the instruments when using tests of the overidentifying restrictions. In these regressions, the Wu-Hausman tests find no evidence of endogeneity of the structural change terms. A possible explanation is that over 1980-96, growth was generally slower than previously, and the shorter timespan implies less scope for shocks to growth to feed back into the observed extent of structural change.

We now discuss the strength of the instruments. As is now well known, when instruments are only weakly correlated with the endogenous explanatory variables, the 2SLS and GMM estimators may be badly biased in small samples. Moreover, the conventional asymptotic approximations used for hypothesis tests and confidence intervals are likely to be unreliable. Studies such as Stock et al. (2002) have recommended, as a rule of thumb, that values for the first-stage Fstatistic (associated with the null that coefficients on excluded instruments are equal to zero) below 10 can indicate a weak instrument problem. Some of our first-stage F-statistics are below this threshold, and for this reason we have also reported estimates based on Fuller's (1977) modification of the LIML estimator. Fuller's estimator can sometimes be more robust than 2SLS in the presence of weak instruments, and is designed to ensure the estimator has finite moments (unlike LIML). It performs relatively well in the simulations carried out in Hahn et al. (2004) and appears to have lower small-sample variability than LIML. We set the user-specified constant (denoted by alpha in Fuller 1977) to a value of one, at which point the estimator is nearly unbiased (Fuller 1977, p. 951). ${ }^{21}$ It can be seen from Table 7 that the use of the Fuller (1) estimator gives results comparable to those obtained with 2SLS and GMM.

An alternative response to weak instrument biases is the use of robust methods for inference, such as those developed by Moreira (2003) and recommended by Stock et al. (2002). Given the potential weakness of our instruments, we have used Moreira's method to construct robust $95 \%$ confidence regions for the

\footnotetext{
${ }^{21}$ The point estimates tend to be slightly smaller in magnitude if we set alpha to four (a value which may improve the performance of the estimator in mean-square error terms) but the reductions are not large enough to modify our overall conclusions.
} 
structural change coefficients, and these are also reported in Table 7. We base these confidence intervals on conditional likelihood ratio tests, which appear to have good power properties (Moreira 2003). As Table 7 shows, these confidence intervals tend to be wide, especially in regressions (31) and (33) where the instruments are especially weak. Nevertheless, zero remains excluded from the intervals for regressions (30)-(33), and the main effect of using a robust interval is that it extends further to the right, so that the evidence is consistent with even higher estimates of the structural change coefficient.

In summary, the message from the IV results is mixed. On the positive side, we can obtain reasonably precise estimates of the coefficients on the structural change terms. There is some evidence from Wu-Hausman tests that these terms are correlated with the disturbances, but we find remarkably little evidence that the OLS estimates of structural change effects are biased away from zero. The pattern we find is the opposite: IV estimates are further away from zero than the OLS estimates. The differences in the coefficients between the OLS and IV results suggest that the expected simultaneity bias is either not present, or has been offset by other factors such as measurement error.

At the same time, there is a need for caution. Our exclusion restrictions are questionable, and the coefficients on the structural change terms are imprecisely estimated under a range of alternative specifications. In particular we find much weaker results (not reported) when using TFP growth as the dependent variable. Then, either the models are only weakly identified, or the standard errors on the structural change terms are too high to draw useful conclusions about the parameter values. In samples of this size, all the coefficient estimates and specification tests may be sensitive to small numbers of observations, but there is no generally agreed-upon method to ensure robustness in the IV context. For all these reasons, we are inclined to place more weight on the OLS findings earlier in the paper. But we must also acknowledge the possible endogeneity of structural change as a key drawback of those results, a weakness shared with previous studies.

\section{The implied parameter values}

So far, we have shown that structural change terms have some explanatory power when included in either standard growth regressions or TFP growth regressions. In this section, we focus on the magnitude of the associated parameter estimates, rather than simply their precision. We calculate the parameter values implied by the OLS results, based on transformations of the regression coefficients, and 
also obtain an alternative set of parameter estimates more directly, by using non-linear least squares (NLS) estimation.

We are able to show that our regression estimates imply marginal product differentials of a similar magnitude to the rural-urban wage differentials sometimes observed in microeconomic data. Moreover, our disequilibrium specification allows the estimated differential to vary across countries, and we calculate and report the extent of this variation. This is not only of independent interest, but also acts as a check that our regression specification and parameter estimates are plausible.

First of all, we briefly discuss the microeconomic evidence on rural-urban wage differentials. This evidence is patchy, with reliable data available for only a small number of countries. The data in World Bank (1995, p. 76) suggest that the urban wage can easily be $30-100 \%$ higher than the rural wage for workers of similar skill levels. As we noted in the introduction, however, wages may depart from marginal products, for example because workers receive their average product in the agricultural sector rather than a marginal product close to zero (Lewis 1954). In this case, marginal product differentials could be much larger than observed wage gaps. Our estimation of a production relationship allows the extent of differentials to be inferred for a large number of countries, at the expense of some strong assumptions. ${ }^{22}$

Using our theoretical model, and a small number of parameter assumptions, the coefficients in our regressions can be used to calculate the values of the parameters in the model. First of all, we focus on obtaining an estimate of $k$, the equilibrium differential, in the restricted model that assumes instantaneous adjustment and therefore excludes the disequilibrium term. We then look at the disequilibrium model, which sets $k=1$ but allows for a slower speed of adjustment (finite $\psi$ ).

There are a few technical issues here that could be skipped by readers interested primarily in the final results and their economic interpretation. First of all, our model is set up in such a way that structural change influences TFP growth. In our MRW-style growth regressions, we have to rescale the coefficients so that they correspond to effects on annual TFP growth rather than overall growth in labour-augmenting efficiency. This is easily done, and we denote the rescaled coefficient on $M G R O W T H$ as $\pi=(k-1) \phi$. In order to calculate the implied

\footnotetext{
${ }^{22}$ It is the marginal product differential, not the wage gap, that will drive our empirical results, because it determines the effects of structural change on TFP growth, and thereby influences the partial correlations observed in the data. In the remainder of this section, we will sometimes use the term 'wage differential' as a convenient shorthand, but our estimates are best seen as relating to the magnitude of the marginal product differential.
} 
$k$, we need an assumption about $\phi=w_{a} L / Y$. This parameter will be close to the aggregate labour share if the agricultural sector accounts for the majority of employment and/or the intersectoral wage gap is not large. We adopt a value of $2 / 3$ for $\phi$, but the order of magnitude of the implied differential does not hinge on the assumption about $\phi$, and our results are not greatly changed by considering $\phi=1 / 2 .^{23}$

Table 8 presents the parameter values implicit in our growth regressions and TFP regressions. The first case is the restricted model, where adjustment is assumed to be instantaneous and hence the disequilibrium term is omitted from the regression. The calculation can be illustrated with an example. In the case of regression (11) in Table 5, the model yields a coefficient estimate on MGROWTH of 75.64. Dividing by the number of years, given that the dependent variable is the log difference of output between 1960 and 1996, and rescaling by one third (to get from labour-augmenting efficiency to TFP growth) yields $\pi=0.70$. This implies a value of $k=2.05$. That is, the marginal product of labour in non-agriculture is roughly double that in agriculture. Across a wide range of models, samples and estimation methods, the implied marginal product ratio lies between 1.8 and 4.5 .

A limitation is that, within a given regression, the wage differential is assumed to be constant across countries. It is therefore interesting to explore the disequilibrium specification, based on regressions that assume a finite speed of adjustment but $k=1$ (that is, no differential in equilibrium). The theoretical model implies that the coefficient on DISEQ is equal to $\phi / \psi$. The coefficient on $D I S E Q$ from regression (12) in Table 5 was 2.00. After rescaling, this implies a value for the speed of adjustment parameter $\psi$ of 0.036 . We can interpret this as follows. In our main sample, the median propensity to migrate $(p)$ is 0.0199 . Using equation (4) this implies a current wage ratio $w_{m} / w_{a}$ of 1.56 for a country with the median value of $p$. In this specification, however, the implicit wage ratio varies across countries. For the country at the 10th percentile of the $p$ distribution, the implied wage ratio is 1.09 , while it is 2.21 at the 90 th percentile. Alternative specifications give similar results. These results are promising in that they indicate low marginal product differentials in some countries (associated with a low propensity to migrate) while in others, the marginal product of labour is substantially higher in non-agriculture than in agriculture.

Another approach is to use non-linear least squares to estimate the parame-

\footnotetext{
${ }^{23}$ Such assumptions may not be unreasonable in the light of Gollin (2002). He argues that the aggregate labour share is not systematically related to the level of development, although it does vary across countries. See Durlauf's comments on Bosworth and Collins (2003) for more discussion.
} 
ters directly. This allows us to replace our assumption that $\phi$ is constant across countries with an assumption that the aggregate labour share $\eta$ is constant across countries. This is done by substituting $\phi$ out of the regression equation, using equation (16) in the Appendix. In the NLS regressions, we assume the aggregate labour share $\eta=2 / 3$. The results are shown in Appendix Table A4, and yield parameter values that are in line with those reported above, although somewhat higher for the TFP growth regressions.

In summary, a wide variety of specifications and estimation methods combine to tell a plausible story. The disequilibrium model, in particular, implies that marginal product differentials are of a similar order of magnitude to those found in microeconomic studies, but are barely present in a subset of economies, namely those where recent structural change has been limited. Another finding, made clear by the last four columns of Table 8 , is that the implied magnitude of the differentials was noticeably lower in 1980-96 than in 1960-80. This is consistent with the view that the extent of dualism has declined over time.

\section{Summary and conclusions}

Current empirical growth models are often criticised for neglecting structural change. When there is a differential in the marginal product of labour across sectors, changes in employment structure will be an independent source of growth in aggregate TFP. This paper presents an empirical growth model which reveals precisely how TFP growth might be affected by structural change, and then seeks to quantify the effect. We have extended otherwise standard growth regressions to include structural change terms, and have also estimated regressions with TFP growth as the dependent variable.

Both approaches lead to essentially the same results: sizeable differentials, of an order of magnitude comparable to microeconomic evidence. There is some evidence of variation across countries, and we also find that the differentials have fallen over time. One of our central findings is that structural change can account for a significant fraction of the international variation in TFP growth. Our regressions for TFP growth that include regional dummies, the initial level of TFP, and structural change terms can explain around half the variation. When structural change terms are excluded, this proportion falls to a third.

The frameworks developed here could be extended in several ways. Above all, it would be interesting to consider alternative aspects of dualism. One obvious modification to the work above would be to assume that agricultural labour receives its average product rather than its marginal product (Lewis 
1954). More generally, it is clear that recent growth research has neglected the implications of two sector models. There are many opportunities for further work in this direction.

\section{Appendix}

This appendix derives an expression for output growth in the presence of a marginal product differential. Given the agricultural production function shown in the main text, agricultural output growth is equal to:

$$
\frac{\dot{Y}_{a}}{Y_{a}}=\frac{\dot{A}_{a}}{A_{a}} \frac{A_{a} F(.)}{Y_{a}}+\frac{A_{a} F_{K} K}{Y_{a}} \frac{\dot{K}_{a}}{K}+\frac{A_{a} F_{L} L}{Y_{a}} \frac{\dot{L}_{a}}{L}
$$

Using (6), (7), the definition $s=Y_{a} / Y$ and the definitions of factor shares, we can write:

$$
s \frac{\dot{Y}_{a}}{Y_{a}}=s \frac{\dot{A}_{a}}{A_{a}}+(1-\eta) \frac{\dot{K}_{a}}{K}+\phi \frac{\dot{L}_{a}}{L}
$$

Output growth in manufacturing is:

$$
\frac{\dot{Y}_{m}}{Y_{m}}=\frac{\dot{A}_{m}}{A_{m}} \frac{A_{m} G(.)}{Y_{m}}+\frac{A_{m} G_{K} K}{Y_{m}} \frac{\dot{K}_{m}}{K}+\frac{A_{m} G_{L} L}{Y_{m}} \frac{\dot{L}_{m}}{L}
$$

Hence we can write:

$$
\begin{aligned}
(1-s) \frac{\dot{Y}_{m}}{Y_{m}} & =(1-s) \frac{\dot{A}_{m}}{A_{m}}+(1-\eta) \frac{\dot{K}_{m}}{K}+\frac{w_{m} L}{Y} \frac{\dot{L}_{m}}{L} \\
& =(1-s) \frac{\dot{A}_{m}}{A_{m}}+(1-\eta) \frac{\dot{K}_{m}}{K}+\phi \frac{\dot{L}_{m}}{L}+\frac{w_{m} L}{Y} \frac{\dot{L}_{m}}{L}-\phi \frac{\dot{L}_{m}}{L}
\end{aligned}
$$

Now we can use our expression for the modern sector wage (4) to obtain:

$$
\begin{aligned}
(1-s) \frac{\dot{Y}_{m}}{Y_{m}}= & (1-s) \frac{\dot{A}_{m}}{A_{m}}+(1-\eta) \frac{\dot{K}_{m}}{K}+\phi \frac{\dot{L}_{m}}{L} \\
& +\frac{k w_{a} L}{Y} \frac{L_{m}}{L} \frac{\dot{L}_{m}}{L_{m}}+\frac{1}{\psi} \frac{p}{1-p} \frac{k w_{a} L}{Y} \frac{L_{m}}{L} \frac{\dot{L}_{m}}{L_{m}}-\phi \frac{L_{m}}{L} \frac{\dot{L}_{m}}{L_{m}}
\end{aligned}
$$

Using $\phi=w_{a} L / Y$ and $L_{m} / L=1-a$ we can rewrite this as:

$$
\begin{aligned}
(1-s) \frac{\dot{Y}_{m}}{Y_{m}}= & (1-s) \frac{\dot{A}_{m}}{A_{m}}+(1-\eta) \frac{\dot{K}_{m}}{K}+\phi \frac{\dot{L}_{m}}{L} \\
& +(k-1) \phi(1-a) \frac{\dot{L}_{m}}{L_{m}}+k \phi(1-a) \frac{1}{\psi} \frac{p}{1-p} \frac{\dot{L}_{m}}{L_{m}}
\end{aligned}
$$


We can combine (13) and (14) and use $\dot{K}_{a}+\dot{K}_{m}=\dot{K}$ and $\dot{L}_{a}+\dot{L}_{m}=\dot{L}$ to obtain an equation for aggregate growth:

$$
\begin{aligned}
\frac{\dot{Y}}{Y}= & (1-\eta) \frac{\dot{K}}{K}+\phi \frac{\dot{L}}{L}+s \frac{\dot{A}_{a}}{A_{a}}+(1-s) \frac{\dot{A}_{m}}{A_{m}}+ \\
& +(k-1) \phi(1-a) \frac{\dot{L}_{m}}{L_{m}}+k \phi \frac{1}{\psi} \frac{p}{1-p}(1-a) \frac{\dot{L}_{m}}{L_{m}}
\end{aligned}
$$

We can simplify this further, as follows. We can define the aggregate labour share as:

$$
\eta=\frac{w_{a} L_{a}+w_{m} L_{m}}{Y}
$$

Equation (4), together with $L_{a}=a L$ and $L_{m}=(1-a) L$ implies:

$$
\eta=\frac{w_{a} a L+\left[k w_{a}+\frac{1}{\psi} \frac{p}{1-p} k w_{a}\right](1-a) L}{Y}
$$

Using $\phi=w_{a} L / Y$ we have

$$
\begin{aligned}
\eta & =\phi\left[a+(1-a) k+\frac{1}{\psi} \frac{p}{1-p}(1-a) k\right] \\
& =\phi\left[1+(1-a)(k-1)+\frac{1}{\psi} \frac{p}{1-p}(1-a) k\right]
\end{aligned}
$$

Hence

$$
\eta-\phi=\phi\left[(1-a)(k-1)+\frac{1}{\psi} \frac{p}{1-p}(1-a) k\right]
$$

Also note that we can write:

$$
\phi \frac{\dot{L}}{L}=\eta \frac{\dot{L}}{L}-(\eta-\phi) \frac{\dot{L}}{L}
$$

Using this relationship, and (16) together with (15) implies that aggregate growth equals

$$
\begin{aligned}
\frac{\dot{Y}}{Y}= & (1-\eta) \frac{\dot{K}}{K}+\eta \frac{\dot{L}}{L}+s \frac{\dot{A}_{a}}{A_{a}}+(1-s) \frac{\dot{A}_{m}}{A_{m}}+ \\
& +(k-1) \phi(1-a)\left[\frac{\dot{L}_{m}}{L_{m}}-\frac{\dot{L}}{L}\right]+k \phi \frac{1}{\psi} \frac{p}{1-p}(1-a)\left[\frac{\dot{L}_{m}}{L_{m}}-\frac{\dot{L}}{L}\right]
\end{aligned}
$$

If we define $m=L_{m} / L=1-a$ then the growth equation can be rewritten as:

$$
\begin{aligned}
\frac{\dot{Y}}{Y}= & (1-\eta) \frac{\dot{K}}{K}+\eta \frac{\dot{L}}{L}+s \frac{\dot{A}_{a}}{A_{a}}+(1-s) \frac{\dot{A}_{m}}{A_{m}}+ \\
& +(k-1) \phi(1-a) \frac{\dot{m}}{m}+k \phi \frac{1}{\psi} \frac{p}{1-p}(1-a) \frac{\dot{m}}{m}
\end{aligned}
$$


which corresponds to the model set out in equations (9) and (10) in the main text.

As described in the text, we can test the implications of the model using regressions with TFP growth as the dependent variable. But much of our empirical work proceeds by adding structural change terms to growth regressions of the MRW form. This has advantages described in the text, but involves some restrictive approximations, which we now describe.

The theoretical derivation in MRW, which leads to a linear regression, is developed for a one sector model with a Cobb-Douglas production function:

$$
Y=K^{\alpha} H^{\beta}(A L)^{1-\alpha-\beta}
$$

where the notation is standard. MRW derive a model in which the change in log output per capita (or per worker) between periods 0 and $t$ is given by

$$
\log \frac{Y(t)}{L(t)}-\log \frac{Y(0)}{L(0)}=\theta \log A(0)+g t+\theta \gamma^{\prime} X-\theta \log \frac{Y(0)}{L(0)}
$$

where $A(0)$ is the initial level of labour-augmenting efficiency, $g$ is the growth rate of efficiency $A, \theta$ is a parameter related to the convergence rate, $X$ is a vector of explanatory variables implied by the model, and $\gamma$ is a vector of slope coefficients that are simple functions of the underlying technology parameters $\alpha$ and $\beta$.

One of the maintained assumptions of MRW is that $g$ is constant across countries. Given the Cobb-Douglas production technology, TFP growth is equal to $g$ times the exponent on the efficiency index, which here is $1-\alpha-\beta$. In the presence of wage differentials, TFP growth will be a function of structural change terms, so our extension of MRW takes the form:

$$
\begin{aligned}
\log \frac{Y(t)}{L(t)}-\log \frac{Y(0)}{L(0)}= & \omega+\frac{t(k-1) \phi}{1-\alpha-\beta} M G R O W T H \\
& +\frac{t k \phi}{(1-\alpha-\beta) \psi} D I S E Q+\theta \gamma^{\prime} X-\theta \log \frac{Y(0)}{L(0)}
\end{aligned}
$$

We use this specification in much of the empirical work. It provides a useful way to estimate growth in aggregate efficiency without using capital stock data. That said, its linear form relies on the Cobb-Douglas production function, the one sector structure of the model, and the simple steady-state solution to which it gives rise. The specification (19) is therefore a hybrid of the Solow model and a two sector framework of the kind set out above. Although not entirely satisfactory, this reflects a long-standing difficulty in deriving a two sector growth model that is simple enough to implement empirically. In two sector models, the 
existence of an aggregate Cobb-Douglas production function and/or a steadystate can only be established under restrictive conditions.

The other necessary approximations are less serious. One of the explanatory variables in the MRW growth regression is $\log (n+g+\delta)$ where $n$ is population or labour force growth, $\delta$ is depreciation and $g+\delta$ is typically assumed to equal 0.05. Our model, in which $g$ varies across countries, weakens the case for treating $g+\delta$ in this way. In principle, a solution would be to substitute MGROWTH and DISEQ into the $\log (n+g+\delta)$ term and estimate the model by non-linear least squares, but this model would be only weakly identified. An alternative and more pragmatic response is to argue that variation in $g$ is likely to be modest in relation to the international variation in population growth $(n)$.

\section{References}

[1] Atkeson, Andrew and Kehoe, Patrick J. (2000). Paths of development for early and late-bloomers in a dynamic Heckscher-Ohlin model. Manuscript, Federal Reserve Bank of Minneapolis.

[2] Bardhan, Pranab K. and Christopher Udry (1999). Development Microeconomics. Oxford: Oxford University Press.

[3] Barro, R. J. (1991). Economic growth in a cross section of countries. Quarterly Journal of Economics, 106(2), 407-443.

[4] Barro, R. J. (1999). Notes on growth accounting. Journal of Economic Growth, 4(2), 119-137.

[5] Barro, Robert J. and Jong-Wha Lee (2001). International data on educational attainment: updates and implications. Oxford Economic Papers 53 (3): 541-563.

[6] Basu, Kaushik (1997). Analytical Development Economics: The Less Developed Economy Revisited. Cambridge, Mass.: MIT Press.

[7] Baum, C. F., Schaffer, M. E. and Stillman, S. (2003). Instrumental variables and GMM: estimation and testing. Stata Journal, 3(1), 1-31.

[8] Bencivenga, V. R. and Smith, B. D. (1997). Unemployment, migration, and growth. Journal of Political Economy, 105(3), 582-608.

[9] Bernanke, Ben S. and Refet S. Gürkaynak (2001). Is Growth Exogenous? Taking Mankiw, Romer, and Weil Seriously. NBER Macroeconomics Annual, 16, 11-57. 
[10] Bertrand, T. and Squire, L. (1980). The relevance of the dual economy model - a case-study of Thailand. Oxford Economic Papers, 32(3), 480-511.

[11] Blackorby, Charles and Schworm, William (1988). The existence of input and output aggregates in aggregate production functions. Econometrica, 56(3), 613-643.

[12] Bosworth, Barry P. and Collins, Susan M. (2003). The empirics of growth: an update. Brookings Papers on Economic Activity, 2, 113-206.

[13] Caselli, Francesco and Coleman, Wilbur John, II (2001). The U.S. structural transformation and regional convergence: a reinterpretation. Journal of Political Economy, 109(3), 584-616.

[14] Chenery, H. and Syrquin, M. (1975). Patterns of development, 1950-1970. Oxford University Press, London.

[15] Chenery, Hollis, Sherman Robinson and Moshe Syrquin (1986). Industrialization and growth: a comparative study. Oxford University Press, New York.

[16] Denison, E. F. (1967). Why growth rates differ: postwar experiences in nine Western countries. Washington: Brookings.

[17] Denison, E. F. (1974). Accounting for United States economic growth 19291969. Washington: Brookings.

[18] Dowrick, S. and Gemmell, N. (1991). Industrialisation, catching up and economic growth: a comparative study across the world's capitalist economies. Economic Journal, 101(405), 263-275.

[19] Echevarria, C. (1997). Changes in sectoral composition associated with economic growth. International Economic Review, 38(2), 431-452.

[20] Feder, Gershon (1983). On exports and economic growth. Journal of Development Economics, 12(1), 59-73.

[21] Feder, Gershon (1986). Growth in semi-industrial countries. In Hollis Chenery, Sherman Robinson and Moshe Syrquin. Industrialization and growth: a comparative study. Oxford University Press, New York.

[22] Felipe, Jesus and Fisher, Franklin M. (2003). Aggregation in Production Functions: What Applied Economists Should Know. Metroeconomica, 54, 208-262. 
[23] Fisher, Franklin M. (1992). Aggregation: aggregate production functions and related topics. Harvester Wheatsheaf, Hemel Hempstead.

[24] Fuller, Wayne A. (1977). Some properties of a modification of the limited information estimator. Econometrica, 45(4), 939-954.

[25] Food and Agricultural Organization of the United Nations (FAO) (2003). FAOSTAT Statistical Databases. http://apps.fao.org/default.htm [22.04.2003].

[26] Galor, Oded and David N. Weil (2000). Population, Technology and Growth: From Malthusian Stagnation to the Demographic Transition and Beyond. American Economic Review, 90, 806-828.

[27] Gemmell, Norman (1996). Evaluating the Impacts of Human Capital Stocks and Accumulation on Economic Growth: Some New Evidence. Oxford Bulletin of Economics and Statistics 58 (1): 9-28.

[28] Gollin, Douglas (2002). Getting income shares right. Journal of Political Economy 110 (2): 458-474.

[29] Gollin, Douglas, Stephen L. Parente and Richard Rogerson (2000). Farm work, home work and international productivity differences. Review of Economic Dynamics, forthcoming.

[30] Gollin, Douglas, Stephen L. Parente and Richard Rogerson (2002). Structural transformation and cross-country income differences. Manuscript, University of Illinois.

[31] Hahn, Jinyong, Jerry Hausman and Guido Kuersteiner (2004). Estimation with weak instruments: accuracy of higher-order bias and MSE approximations. Econometrics Journal, 7, 272-306.

[32] Hansen, Gary and Prescott, Edward C. (2002). Malthus to Solow. American Economic Review, 60, 895-911.

[33] Harris, John R., and Michael P. Todaro (1970). Migration, unemployment and development: a two-sector analysis. American Economic Review, 60(1), 126-142.

[34] Heston, Alan, Robert Summers, Bettina Aten (2002). Penn World Table Version 6.1. Center for International Comparisons at the University of Pennsylvania, October. http://pwt.econ.upenn.edu. 
[35] Imbs, Jean and Wacziarg, Romain (2003). Stages of diversification. American Economic Review, 93(1), 63-86.

[36] Kelley, A. C. and Williamson, J. G. (1973). Sources of growth methodology in low-income countries: a critique. Quarterly Journal of Economics, 87(1), 138-147.

[37] Klenow, Peter and Rodriguez-Clare, Andres (1997). The neoclassical revival in growth economics: has it gone too far? NBER Macroeconomics Annual, 73-103.

[38] Koenker, Roger, and Kevin F. Hallock (2001). Quantile Regression. Journal of Economic Perspectives, 15(4), 143-156.

[39] Kongsamut, Piyabha, Rebelo, Sergio and Xie, Danyang (2001). Beyond balanced growth. Review of Economic Studies, 68(4), 869-882.

[40] Kuznets, Simon (1961). Economic growth and the contribution of agriculture: notes on measurement. International Journal of Agrarian Affairs, $3(1), 56-75$.

[41] Kuznets, Simon (1971). Economic growth of nations: total output and production structure. Harvard University Press, Cambridge, MA.

[42] Laitner, John (2000). Structural change and economic growth. Review of Economic Studies, 67(3), 545-561.

[43] Landon-Lane, John and Robertson, Peter E. (2003) Accumulation and productivity growth in industrializing economies. Manuscript, UNSW, Australia.

[44] Lewis, W. Arthur (1954). Economic Development with Unlimited Supplies of Labour. Manchester School of Economic and Social Studies, 22(2), 139191.

[45] Lucas, Robert E. Jr. (2004). Life Earnings and Rural-Urban Migration. Journal of Political Economy, 112 (1, pt. 2): S29-S59.

[46] Mankiw, N. G., Romer, D. and Weil, D. (1992). A contribution to the empirics of economic growth. Quarterly Journal of Economics, 107(2), 407437.

[47] Mas-Colell, A. and Razin, A. (1973). A model of intersectoral migration and growth. Oxford Economic Papers, 25(1), 72-79. 
[48] May, Kenneth (1946). The aggregation problem for a one-industry model. Econometrica, 14(1), 285-298.

[49] Mazumdar, Dipak (1987). Rural-urban migration in developing countries. In Edwin S. Mills (ed.) Handbook of Regional and Urban Economics Volume II, North-Holland, Amsterdam.

[50] Moreira, Marcelo J. (2003). A conditional likelihood ratio test for structural models. Econometrica, 71(4), 1027-1048.

[51] Moreira, Marcelo J. and Poi, Brian P. (2003). Implementing conditional tests with correct size in the simultaneous equations model. Stata Journal, $1(1), 1-15$.

[52] Naqvi, S. N. H. (1996). The significance of development economics. World Development, 24(6), 975-987.

[53] Neary, J. P. (1978). Dynamic stability and the theory of factor-market distortions. American Economic Review, 68(4), 671-682.

[54] Ngai, L. Rachel and Pissarides, Christopher (2004). Structural change in a multi-sector model of growth. CEP Discussion paper no. 627, London School of Economics, June.

[55] Paci, R. and Pigliaru, F. (1999). Is dualism still a source of convergence in Europe? Applied Economics, 31(11), 1423-1436.

[56] Pack, H. (1992). Technology gaps between industrial and developing countries: are there dividends for latecomers? In Lawrence H. Summers and Shekhar Shah (eds.) Proceedings of the World Bank Annual Conference on Development Economics, 1992.

[57] Parente, Stephen L., Richard Rogerson and Randall Wright (2000). Homework in Development Economics: Household Production and the Wealth of Nations. Journal of Political Economy, 108(4), 680-687.

[58] Poirson, H. (2000). Factor reallocation and growth in developing countries. IMF working paper no. WP/00/94, June.

[59] Poirson, H. (2001). The impact of intersectoral labour reallocation on economic growth. Journal of African Economies, 10(1), 37-63.

[60] Pritchett, Lant (2000). The tyranny of concepts: CUDIE (cumulated, depreciated, investment effort) is not capital. Journal of Economic Growth, $5(4), 361-384$. 
[61] Pritchett, Lant (2001). Where has all the education gone? World Bank Economic Review, 15(3), 367-391.

[62] Pu, Shou Shan (1946). A note on macroeconomics. Econometrica, 14(4), 299-302.

[63] Ray, Debraj (1998). Development Economics. Princeton University Press.

[64] Robertson, Peter E. (1999). Economic growth and the return to capital in developing economies. Oxford Economic Papers, 57(4), 577-594.

[65] Robinson, S. (1971). Sources of growth in less developed countries: a crosssection study. Quarterly Journal of Economics, 85(3), 391-408.

[66] Ruttan, V. (1998). The new growth theory and development economics: a survey. Journal of Development Studies, 35(2), 1-26.

[67] Schmitt, G. (1989). Simon Kuznets' "Sectoral Shares in Labour Force": a different explanation of his $(\mathrm{I}+\mathrm{S}) /$ A ratio. American Economic Review, $79(5), 1262-1276$.

[68] Stern, N. (1991). The determinants of growth. Economic Journal, 101(404), 122-133.

[69] Stock, James H., Jonathan H. Wright and Motohiro Yogo (2002). A survey of weak instruments and weak identification in generalized method of moments. Journal of Business and Economic Statistics, 20(4), 518-529.

[70] Syrquin, M. (1984). Resource reallocation and productivity growth. In Moshe Syrquin, Lance Taylor and Larry E. Westphal (eds.) Economic structure and performance. Academic Press, London.

[71] Syrquin, M. (1986). Productivity growth and factor reallocation. In Hollis Chenery, Sherman Robinson and Moshe Syrquin. Industrialization and growth: a comparative study. Oxford University Press, New York.

[72] Temple, Jonathan R. W. (2001). Structural change and Europe's Golden Age. University of Bristol discussion paper no. 01/519.

[73] Wacziarg, Romain (2001). Structural convergence. Manuscript, Stanford University.

[74] Weil, David N. (2004). Economic growth. Pearson. 
[75] White, Hal (1980). A heteroskedasticity-consistent covariance matrix estimator and a direct test for heteroskedasticity. Econometrica, 48, 817-838.

[76] World Bank (1995). World Development Report. OUP, World Bank.

[77] World Bank (2002). World Development Indicators 2002 CD-ROM. Washington, D.C.: The World Bank. 


\section{Table 1}

Employment and output shares of agriculture in 1960, 1980 and 1996

\begin{tabular}{l|ccc|ccc|ccc|ccc}
\hline \hline & \multicolumn{4}{|c|}{$a$} & \multicolumn{3}{|c|}{$s$} & \multicolumn{4}{c|}{$R L P$} & \multicolumn{3}{c}{ Sample sizes } \\
& 1960 & 1980 & 1996 & 1960 & 1980 & 1996 & 1960 & 1980 & 1996 & $a$ & $s$ & $R L P$ \\
\hline Sub-Saharan Africa & 0.88 & 0.76 & 0.71 & 0.39 & 0.30 & 0.37 & 11.8 & 8.7 & 6.1 & 19 & 16 & 16 \\
Middle East and North Africa & 0.55 & 0.28 & 0.19 & - & - & - & - & - & - & 4 & 0 & 0 \\
East Asia and Pacific & 0.62 & 0.39 & 0.17 & 0.29 & 0.19 & 0.08 & 3.4 & 3.3 & 2.8 & 10 & 8 & 7 \\
South Asia & 0.75 & 0.70 & 0.60 & 0.46 & 0.34 & 0.25 & 3.2 & 3.2 & 3.4 & 5 & 4 & 4 \\
Latin America and the Caribbean & 0.53 & 0.36 & 0.23 & 0.23 & 0.12 & 0.09 & 3.8 & 3.4 & 2.2 & 20 & 18 & 18 \\
High income OECD & 0.19 & 0.08 & 0.05 & 0.11 & 0.05 & 0.03 & 2.4 & 1.8 & 1.7 & 20 & 16 & 16 \\
\hline \hline
\end{tabular}

Notes. Medians within each country grouping. Own calculations based on FAO (2003) and World Bank (2002); see text for details. $a=$ share of agriculture in total employment. $s=$ share of agriculture in total value added. $R L P=$ ratio of average labor productivity in non-agriculture to that in agriculture (cf. text). Sample sizes $=$ Number of countries in the regional sample.

Table 2

Propensity to migrate, $1960-96$

\begin{tabular}{ll}
\hline \hline Five highest & \\
\hline Singapore & $9.8 \%$ \\
Japan & $5.2 \%$ \\
France & $4.7 \%$ \\
Canada & $4.4 \%$ \\
Korea, Republic of & $4.4 \%$ \\
\hline Five lowest & \\
\hline Malawi & $0.29 \%$ \\
Ghana & $0.25 \%$ \\
Mozambique & $0.22 \%$ \\
Niger & $0.17 \%$ \\
Nepal & $0.05 \%$ \\
\hline \hline
\end{tabular}

Notes. Calculated as $-(\log (a 96)-\log (a 60)) / 36$ where $a Y Y$ is the agricultural employment share in year 19YY. 
Table 3

Correlations in 76-country sample

\begin{tabular}{|c|c|c|c|c|c|c|c|c|c|c|}
\hline & $D Y$ & $\ln (\operatorname{Inv})$ & $\ln (Y R S C H)$ & $\ln (n+g+\delta)$ & $\ln (G D P 60)$ & MGROWTH & DISEQ & MGROWTH2 & DISEQ2 & $a 60$ \\
\hline$D Y$ & 1.00 & 0.56 & 0.42 & -0.27 & 0.07 & 0.34 & 0.47 & 0.42 & 0.55 & -0.24 \\
\hline $\ln ($ Investment $)$ & & 1.00 & 0.71 & -0.25 & 0.50 & 0.22 & 0.46 & 0.16 & 0.48 & -0.59 \\
\hline $\ln (Y R S C H)$ & & & 1.00 & -0.34 & 0.74 & 0.18 & 0.40 & 0.19 & 0.45 & -0.84 \\
\hline $\ln (n+g+\delta)$ & & & & 1.00 & -0.41 & 0.08 & -0.15 & -0.14 & -0.32 & 0.44 \\
\hline $\ln (G D P 60)$ & & & & & 1.00 & 0.15 & 0.39 & 0.15 & 0.42 & -0.89 \\
\hline MGROWTH & & & & & & 1.00 & 0.81 & 0.81 & 0.73 & 0.00 \\
\hline DISEQ & & & & & & & 1.00 & 0.64 & 0.93 & -0.34 \\
\hline MGROWTH2 & & & & & & & & 1.00 & 0.76 & -0.04 \\
\hline DISEQ2 & & & & & & & & & 1.00 & -0.39 \\
\hline$a 60$ & & & & & & & & & & 1.00 \\
\hline
\end{tabular}

Notes. DY is the log difference of GDP per worker, 1960-96. In(Investment) is the log of the investment share of GDP per capita, averaged over 1960-96. $\ln (Y R S C H)$ is the log of the average years of schooling in the working-age population, averaged over 1960-95. $\ln (n+g+\delta)$ includes labor-force growth (n), productivity growth $(g)$ and depreciation $(\delta)$, $1960-$ 96, where $g+\delta=0.05$. $\ln (G D P 60)$ is the log of GDP per worker in 1960. MGROWTH, DISEQ, MGROWTH2, and DISEQ2 are structural change terms calculated for 1960-96, as defined in the text. a60 is the agricultural employment share in 1960. 
Table 4

Structural change effects in the MRW model

\begin{tabular}{|c|c|c|c|c|c|c|c|c|c|}
\hline & (1) & (2) & (3) & (4) & (5) & (6) & (7) & (8) & (9) \\
\hline Period & 1960-85 & 1960-85 & 1960-85 & $1960-85$ & $1960-96$ & 1960-96 & $1960-96$ & $1960-80$ & 1980-96 \\
\hline Observations & 91 & 76 & 76 & 76 & 76 & 76 & 76 & 76 & 76 \\
\hline \multirow[t]{2}{*}{$\ln ($ Investment $)$} & $0.35^{*}$ & $0.33^{*}$ & $0.32^{*}$ & $0.25^{*}$ & $0.40^{*}$ & $0.46^{*}$ & $0.39^{*}$ & $0.26^{*}$ & $0.35^{+}$ \\
\hline & $(0.06)$ & $(0.07)$ & $(0.08)$ & $(0.08)$ & $(0.14)$ & $(0.16)$ & $(0.14)$ & $(0.06)$ & $(0.13)$ \\
\hline \multirow[t]{2}{*}{$\ln (S C H O O L)$} & $0.26^{*}$ & $0.30^{*}$ & & & & & & & \\
\hline & $(0.06)$ & $(0.07)$ & & & & & & & \\
\hline \multirow[t]{2}{*}{$\ln (Y R S C H)$} & & & $0.24^{*}$ & $0.24^{*}$ & $0.39^{*}$ & $0.38^{*}$ & $0.40^{*}$ & $0.15^{*}$ & 0.15 \\
\hline & & & (0.09) & $(0.07)$ & $(0.10)$ & $(0.11)$ & $(0.10)$ & $(0.05)$ & $(0.11)$ \\
\hline \multirow[t]{2}{*}{$\ln (n+g+\delta)$} & -0.36 & $-0.45^{\circ}$ & -0.29 & $-0.58^{+}$ & $-1.25^{*}$ & $-1.41^{*}$ & $-1.21^{*}$ & $-0.49^{+}$ & $-1.05^{*}$ \\
\hline & $(0.25)$ & $(0.25)$ & $(0.28)$ & $(0.29)$ & $(0.39)$ & $(0.38)$ & $(0.31)$ & $(0.24)$ & $(0.20)$ \\
\hline \multirow[t]{2}{*}{$\ln (G D P 60)$} & $-0.31^{*}$ & $-0.31^{*}$ & $-0.26^{*}$ & $-0.32^{*}$ & $-0.45^{*}$ & $-0.42^{*}$ & $-0.46^{*}$ & $-0.21^{*}$ & $-0.23^{*}$ \\
\hline & $(0.05)$ & $(0.06)$ & $(0.08)$ & $(0.07)$ & $(0.10)$ & $(0.10)$ & $(0.10)$ & $(0.05)$ & $(0.09)$ \\
\hline \multirow[t]{2}{*}{ MGROWTH } & & & & 30.56 & 18.64 & $84.48^{*}$ & & $48.70^{+}$ & 11.79 \\
\hline & & & & (30.23) & $(53.36)$ & (23.59) & & $(22.24)$ & $(23.69)$ \\
\hline \multirow[t]{2}{*}{ DISEQ } & & & & 1.04 & 1.89 & & $2.27^{*}$ & 0.22 & 0.27 \\
\hline & & & & $(0.66)$ & $(1.20)$ & & $(0.44)$ & $(0.44)$ & $(0.42)$ \\
\hline \multirow[t]{2}{*}{ Constant } & $3.84^{*}$ & $3.62^{*}$ & $2.36^{+}$ & 1.71 & 1.24 & 0.64 & 1.41 & 1.14 & -0.19 \\
\hline & $(0.74)$ & $(0.79)$ & $(0.94)$ & $(1.03)$ & $(1.48)$ & $(1.47)$ & $(1.18)$ & $(0.86)$ & $(0.95)$ \\
\hline$R^{2}$ & 0.52 & 0.51 & 0.43 & 0.59 & 0.59 & 0.57 & 0.59 & 0.61 & 0.50 \\
\hline s.e. & 0.30 & 0.30 & 0.32 & 0.27 & 0.42 & 0.42 & 0.41 & 0.23 & 0.28 \\
\hline$F$ (struct. change) & & & & 28.59 & 13.24 & & & 33.73 & 2.87 \\
\hline Prob. $>F$ & & & & 0.0000 & 0.0000 & & & 0.0000 & 0.0637 \\
\hline
\end{tabular}

Notes. Dependent variable: log difference of GDP per worker over the specified period. White heteroscedasticityconsistent standard errors in parentheses. DISEQ re-scaled by multiplying by 1000 . Significance level: ${ }^{*} 1 \% ;^{+} 5 \%$; $\circ 10 \%$. 
Table 5

Structural change effects in the MRW model, 1960-96: further evidence

\begin{tabular}{|c|c|c|c|c|c|c|c|c|c|c|}
\hline & (10) & (11) & (12) & (13) & (14) & (15) & (16) & (17) & (18) & (19) \\
\hline Observations & 76 & 76 & 76 & 76 & 66 & 66 & 66 & 56 & 56 & 56 \\
\hline \multirow[t]{2}{*}{$\ln ($ Investment $)$} & $0.28^{\circ}$ & $0.33^{\circ}$ & $0.28^{\circ}$ & $0.28^{\circ}$ & $0.34^{\circ}$ & $0.40^{+}$ & $0.31^{\circ}$ & $0.30^{\circ}$ & $0.35^{\circ}$ & $0.31^{\circ}$ \\
\hline & $(0.16)$ & $(0.17)$ & $(0.15)$ & $(0.16)$ & $(0.20)$ & $(0.20)$ & $(0.18)$ & $(0.18)$ & $(0.19)$ & $(0.18)$ \\
\hline \multirow[t]{2}{*}{$\ln (Y R S C H)$} & $0.39^{*}$ & $0.38^{*}$ & $0.39^{*}$ & 0.27 & $0.40^{*}$ & $0.40^{*}$ & $0.39^{*}$ & $0.38^{*}$ & $0.37^{*}$ & $0.38^{*}$ \\
\hline & $(0.10)$ & $(0.11)$ & $(0.10)$ & $(0.17)$ & $(0.12)$ & $(0.13)$ & $(0.12)$ & $(0.11)$ & $(0.12)$ & $(0.11)$ \\
\hline \multirow[t]{2}{*}{$\ln (n+g+\delta)$} & $-1.43^{*}$ & $-1.43^{*}$ & $-1.43^{*}$ & $-1.34^{*}$ & $-1.14^{+}$ & $-1.13^{+}$ & $-1.18^{+}$ & $-1.75^{+}$ & $-1.57^{+}$ & $-1.75^{+}$ \\
\hline & $(0.48)$ & $(0.49)$ & $(0.47)$ & $(0.50)$ & $(0.48)$ & $(0.50)$ & $(0.50)$ & $(0.72)$ & $(0.76)$ & $(0.71)$ \\
\hline \multirow[t]{2}{*}{$\ln (G D P 60)$} & $-0.37^{*}$ & $-0.33^{*}$ & $-0.37^{*}$ & $-0.49^{*}$ & $-0.34^{*}$ & $-0.29^{*}$ & $-0.36^{*}$ & $-0.40^{*}$ & $-0.32^{*}$ & $-0.40^{*}$ \\
\hline & $(0.09)$ & (0.09) & (0.09) & $(0.14)$ & $(0.10)$ & $(0.10)$ & (0.09) & $(0.12)$ & $(0.11)$ & $(0.11)$ \\
\hline \multirow[t]{2}{*}{ MGROWTH } & -1.27 & $75.64^{*}$ & & 49.60 & & & & -8.63 & $75.07^{+}$ & \\
\hline & (43.09) & (19.29) & & (55.95) & & & & $(50.48)$ & $(32.92)$ & \\
\hline \multirow[t]{2}{*}{ DISEQ } & $2.02^{+}$ & & $2.00^{*}$ & 1.14 & & & & $2.57^{\circ}$ & & $2.40^{*}$ \\
\hline & $(0.96)$ & & $(0.39)$ & (1.09) & & & & (1.32) & & $(0.74)$ \\
\hline \multirow[t]{2}{*}{ MGROWTH2 } & & & & & 56.86 & $173.36^{*}$ & & & & \\
\hline & & & & & (81.73) & $(40.92)$ & & & & \\
\hline \multirow[t]{2}{*}{ DISEQ2 } & & & & & 3.46 & & $4.61^{*}$ & & & \\
\hline & & & & & $(2.11)$ & & $(1.11)$ & & & \\
\hline \multirow[t]{2}{*}{$a 60$} & & & & -0.75 & & & & & & \\
\hline & & & & $(0.76)$ & & & & & & \\
\hline \multirow[t]{2}{*}{ Constant } & 0.27 & -0.11 & 0.26 & 1.96 & 0.68 & 0.31 & 0.78 & -0.29 & -0.54 & -0.33 \\
\hline & $(1.52)$ & $(1.53)$ & $(1.46)$ & $(2.37)$ & (1.53) & $(1.54)$ & $(1.48)$ & $(1.85)$ & $(1.96)$ & $(1.77)$ \\
\hline$R^{2}$ & 0.69 & 0.67 & 0.69 & 0.70 & 0.71 & 0.70 & 0.71 & 0.67 & 0.64 & 0.67 \\
\hline s.e. & 0.37 & 0.38 & 0.37 & 0.37 & 0.38 & 0.39 & 0.38 & 0.43 & 0.44 & 0.42 \\
\hline$F$ (struct. change) & 12.66 & & & 14.80 & 10.00 & & & 5.20 & & \\
\hline Prob. $>F$ & 0.0000 & & & 0.0000 & 0.0002 & & & 0.0092 & & \\
\hline
\end{tabular}

Notes. Dependent variable: log difference of GDP per worker, 1960-96. All regressions control for regional dummies; coefficients on regional dummies not reported. White heteroscedasticity-consistent standard errors in parentheses. DISEQ and DISEQ2 re-scaled by multiplying by 1000. Coefficients on regional dummies not reported. Significance level: ${ }^{*} 1 \% ;{ }^{+} 5 \% ;{ }^{\circ} 10 \%$. 
Table 6

Structural change effects on TFP growth

\begin{tabular}{|c|c|c|c|c|c|c|c|c|c|c|}
\hline & (20) & (21) & (22) & (23) & (24) & (25) & (26) & (27) & (28) & (29) \\
\hline TFP series & KR & KR & KR & KR & KR & KR & BG & BG & BG & $\mathrm{BC}$ \\
\hline Period & $1960-85$ & 1960-85 & $1960-85$ & $1960-85$ & $1960-85$ & $1960-85$ & 1965-95 & $1965-95$ & 1965-95 & $1960-2000$ \\
\hline Observations & 75 & 75 & 75 & 66 & 66 & 66 & 75 & 48 & 48 & 61 \\
\hline MGROWTH & $\begin{array}{r}47.58 \\
(58.09)\end{array}$ & $\begin{array}{l}104.32^{*} \\
(20.82)\end{array}$ & & & & & $\begin{array}{c}-162.20 \\
(109.33)\end{array}$ & & & \\
\hline DISEQ & $\begin{array}{r}1.54 \\
(1.27)\end{array}$ & & $\begin{array}{r}2.51^{*} \\
(0.42)\end{array}$ & & & & $\begin{array}{r}5.46^{+} \\
(2.25)\end{array}$ & & & \\
\hline MGROWTH2 & & & & $\begin{array}{l}-54.20 \\
(73.45)\end{array}$ & $\begin{array}{l}140.30^{*} \\
(51.25)\end{array}$ & & & $\begin{array}{c}-124.04 \\
(221.21)\end{array}$ & & $\begin{array}{r}-22.74 \\
(126.80)\end{array}$ \\
\hline DISEQ2 & & & & $\begin{array}{r}6.71^{*} \\
(1.90)\end{array}$ & & $\begin{array}{r}5.53^{*} \\
(1.20)\end{array}$ & & $\begin{array}{r}7.45 \\
(4.86)\end{array}$ & $\begin{array}{r}5.20^{\circ} \\
(2.74)\end{array}$ & $\begin{array}{r}4.88^{\circ} \\
(2.56)\end{array}$ \\
\hline $\ln (T F P 60)$ & $\begin{array}{l}-1.16^{*} \\
(0.30)\end{array}$ & $\begin{array}{l}-1.04^{*} \\
(0.30)\end{array}$ & $\begin{array}{l}-1.21^{*} \\
(0.31)\end{array}$ & $\begin{array}{l}-1.31^{*} \\
(0.29)\end{array}$ & $\begin{array}{c}-1.05^{*} \\
(0.30)\end{array}$ & $\begin{array}{l}-1.26^{*} \\
(0.27)\end{array}$ & $\begin{array}{l}-1.43^{*} \\
(0.38)\end{array}$ & $\begin{array}{l}-1.48^{*} \\
(0.48)\end{array}$ & $\begin{array}{l}-1.47^{*} \\
(0.47)\end{array}$ & \\
\hline Constant & $\begin{array}{r}-0.07 \\
(0.22) \\
\end{array}$ & $\begin{array}{r}-0.11 \\
(0.21) \\
\end{array}$ & $\begin{array}{r}0.03 \\
(0.19) \\
\end{array}$ & $\begin{array}{r}-0.04 \\
(0.20) \\
\end{array}$ & $\begin{array}{r}-0.13 \\
(0.22) \\
\end{array}$ & $\begin{array}{r}-0.10 \\
(0.17) \\
\end{array}$ & $\begin{array}{r}-0.41 \\
(0.51) \\
\end{array}$ & $\begin{array}{r}-0.90 \\
(0.54) \\
\end{array}$ & $\begin{array}{c}-1.08^{*} \\
(0.40) \\
\end{array}$ & $\begin{array}{r}0.86^{*} \\
(0.25) \\
\end{array}$ \\
\hline $\begin{array}{l}R^{2} \\
\text { s.e. }\end{array}$ & $\begin{array}{l}0.50 \\
0.46\end{array}$ & $\begin{array}{l}0.49 \\
0.46\end{array}$ & $\begin{array}{l}0.49 \\
0.46\end{array}$ & $\begin{array}{l}0.54 \\
0.45\end{array}$ & $\begin{array}{l}0.47 \\
0.47\end{array}$ & $\begin{array}{l}0.54 \\
0.44\end{array}$ & $\begin{array}{l}0.47 \\
0.94\end{array}$ & $\begin{array}{l}0.36 \\
1.14\end{array}$ & $\begin{array}{l}0.35 \\
1.13\end{array}$ & $\begin{array}{l}0.46 \\
0.58\end{array}$ \\
\hline $\begin{array}{l}F \text { (stru. change) } \\
\text { Prob. }>F\end{array}$ & $\begin{array}{r}19.61 \\
0.0000\end{array}$ & & & $\begin{array}{r}11.11 \\
0.0001\end{array}$ & & & $\begin{array}{r}3.60 \\
0.0326\end{array}$ & $\begin{array}{r}1.85 \\
0.1706\end{array}$ & & $\begin{array}{r}3.60 \\
0.0342\end{array}$ \\
\hline
\end{tabular}

Notes. Dependent variable: Average annual growth rate of total factor productivity, in percent. All regressions control for regional dummies; coefficients on regional dummies not reported. White heteroscedasticity-consistent standard errors in parentheses. DISEQ and DISEQ2 re-scaled by multiplying by 1000. TFP series: KR $=$ Klenow and Rodriguez-Clare (1997); BG = Bernanke and Gürkaynak (2001); BC = Bosworth and Collins (2003). Significance level: ${ }^{*} 1 \% ;{ }^{+} 5 \% ;{ }^{\circ} 10 \%$. 
Table 7

Structural change and growth: instrumental variable results

\begin{tabular}{|c|c|c|c|c|c|c|}
\hline Regression & (30) & (31) & (32) & (33) & (34) & (35) \\
\hline Model & 1 & 1 & 2 & 2 & 2 & 2 \\
\hline Time period & $1960-96$ & $1960-96$ & $1960-96$ & $1960-96$ & $1980-96$ & $1980-96$ \\
\hline Observations & 76 & 76 & 66 & 66 & 61 & 61 \\
\hline \multicolumn{7}{|l|}{ MGROWTH } \\
\hline OLS & $\begin{array}{c}75.64^{*} \\
(19.29)\end{array}$ & & $\begin{array}{l}173.36^{*} \\
(40.92)\end{array}$ & & $\begin{array}{l}34.18^{\circ} \\
(18.15)\end{array}$ & \\
\hline 2SLS & $\begin{array}{l}129.28^{+} \\
(53.41)\end{array}$ & & $\begin{array}{c}294.11^{*} \\
(100.86)\end{array}$ & & $\begin{array}{r}46.00 \\
(31.76)\end{array}$ & \\
\hline GMM & $\begin{array}{l}129.28^{+} \\
(58.49)\end{array}$ & & $\begin{array}{l}298.22^{*} \\
(91.47)\end{array}$ & & $\begin{array}{r}45.59^{\circ} \\
(26.11)\end{array}$ & \\
\hline Fuller (1) & $\begin{array}{l}125.02^{+} \\
(51.34)\end{array}$ & & $\begin{array}{l}286.33^{*} \\
(97.80)\end{array}$ & & $\begin{array}{r}45.85 \\
(31.58)\end{array}$ & \\
\hline \multicolumn{7}{|l|}{ DISEQ } \\
\hline OLS & & $\begin{array}{c}2.00^{*} \\
(0.39)\end{array}$ & & $\begin{array}{c}4.61^{*} \\
(1.11)\end{array}$ & & $\begin{array}{r}0.74^{\circ} \\
(0.44)\end{array}$ \\
\hline 2SLS & & $\begin{array}{r}4.07^{+} \\
(1.75)\end{array}$ & & $\begin{array}{c}9.06^{*} \\
(3.22)\end{array}$ & & $\begin{array}{r}1.48 \\
(0.97)\end{array}$ \\
\hline GMM & & $\begin{array}{c}4.07^{+} \\
(1.78)\end{array}$ & & $\begin{array}{c}9.12^{*} \\
(2.73)\end{array}$ & & $\begin{array}{r}1.52^{\circ} \\
(0.86)\end{array}$ \\
\hline Fuller (1) & & $\begin{array}{l}3.77^{+} \\
(1.59)\end{array}$ & & $\begin{array}{c}8.60^{*} \\
(3.02)\end{array}$ & & $\begin{array}{r}1.43 \\
(0.94)\end{array}$ \\
\hline $\begin{array}{l}\text { Robust } 95 \% \\
\text { confidence interval }\end{array}$ & $\begin{array}{r}{[22.46} \\
287.37]\end{array}$ & $\begin{array}{l}{[0.72} \\
15.35]\end{array}$ & $\begin{array}{l}{[92.61} \\
578.50]\end{array}$ & $\begin{array}{l}{[2.73} \\
23.94]\end{array}$ & $\begin{array}{l}{[-17.64} \\
120.02]\end{array}$ & $\begin{array}{r}{[-0.46,} \\
3.88]\end{array}$ \\
\hline Instrument set & POPAGE & POPAGE & $\begin{array}{l}\text { POPAGE } \\
\text { LRLP60 }\end{array}$ & $\begin{array}{l}\text { POPAGE } \\
\text { LRLP60 }\end{array}$ & $\begin{array}{l}\text { POPAGE } \\
\text { MG6080 }\end{array}$ & $\begin{array}{c}\text { POPAGE } \\
\text { DISEQ6080 }\end{array}$ \\
\hline First stage F-statistic & 14.32 & 6.75 & 8.70 & 4.98 & 28.04 & 9.65 \\
\hline Sargan P-value & - & - & 0.72 & 0.80 & 0.50 & 0.71 \\
\hline J-statistic P-value & - & - & 0.77 & 0.83 & 0.38 & 0.63 \\
\hline Pagan-Hall P-value & 0.28 & 0.57 & 0.15 & 0.29 & 0.03 & 0.04 \\
\hline Wu-Hausman P-value & 0.29 & 0.20 & 0.19 & 0.13 & 0.79 & 0.45 \\
\hline
\end{tabular}

Notes. Dependent variable: log difference of GDP per worker. Entries in table are coefficients and standard errors on MGROWTH or DISEQ in growth regressions, treating the structural change term as endogenous. Coefficients are not comparable across Model 1 and Model 2, or different time periods. All regressions include regional dummies and the MRW controls; these coefficients not reported. Significance level: ${ }^{*} 1 \%{ }^{+}{ }^{+} 5 \% ;{ }^{\circ} 10 \%$. Fuller (1) is the Fuller modification of LIML with alpha=1 (see text). Robust confidence intervals constructed using conditional likelihood ratio tests developed by Moreira (2003). Null hypotheses of specification tests are overidentifying restrictions valid (Sargan for 2SLS, J-statistic for GMM); system homoskedastic (Pagan-Hall, for 2SLS); regressor exogenous (WuHausman, for 2SLS). 
Table 8

Implied parameter values in the growth and TFP regressions

\begin{tabular}{|c|c|c|c|c|c|c|c|c|c|c|}
\hline \multirow{3}{*}{$\begin{array}{l}\text { Dependent variable } \\
\text { Time period } \\
\text { Sample }\end{array}$} & \multirow{2}{*}{\multicolumn{2}{|c|}{$\begin{array}{l}\text { Growth } \\
1960-96\end{array}$}} & \multirow{2}{*}{\multicolumn{2}{|c|}{$\begin{array}{l}\text { TFP-KR } \\
1960-85\end{array}$}} & \multirow{2}{*}{\multicolumn{2}{|c|}{$\begin{array}{l}\text { TFP-BG } \\
1965-95\end{array}$}} & \multicolumn{2}{|c|}{ Growth } & \multicolumn{2}{|c|}{ TFP-BG } \\
\hline & & & & & & & \multirow{2}{*}{$\begin{array}{c}60-80 \\
\text { all }\end{array}$} & \multirow{2}{*}{$\begin{array}{c}80-96 \\
\text { all }\end{array}$} & \multirow{2}{*}{$\begin{array}{c}65-80 \\
\text { all }\end{array}$} & \multirow{2}{*}{$\begin{array}{c}80-95 \\
\text { all }\end{array}$} \\
\hline & all & dev. & all & dev. & all & dev. & & & & \\
\hline \multicolumn{11}{|c|}{ Restricted model with $\psi=\infty$} \\
\hline$k$ & 2.05 & 2.04 & 2.56 & 2.68 & 1.79 & 1.76 & 2.34 & 1.47 & 2.88 & 1.17 \\
\hline \multicolumn{11}{|c|}{ Restricted model wit $k=1$} \\
\hline$\psi$ & 0.036 & 0.030 & 0.027 & 0.022 & 0.028 & 0.023 & 0.037 & 0.084 & 0.024 & 0.044 \\
\hline \multicolumn{11}{|l|}{$w_{m} / w_{a}$} \\
\hline $10^{\text {th }}$ percentile & 1.09 & 1.10 & 1.13 & 1.14 & 1.12 & 1.15 & 1.07 & 1.05 & 1.13 & 1.09 \\
\hline Median & 1.56 & 1.42 & 1.76 & 1.60 & 1.78 & 1.55 & 1.51 & 1.21 & 1.86 & 1.40 \\
\hline $90^{\text {th }}$ percentile & 2.21 & 2.18 & 2.64 & 2.60 & 2.61 & 2.64 & 2.23 & 1.52 & 3.00 & 1.99 \\
\hline
\end{tabular}

Notes. Model 1 specification. All underlying growth regressions control for the four MRW variables and regional dummies. All underlying TFP regressions control for regional dummies and initial TFP. 
Figure 1

Convexity in the relationship between growth and structural change, 1960-96

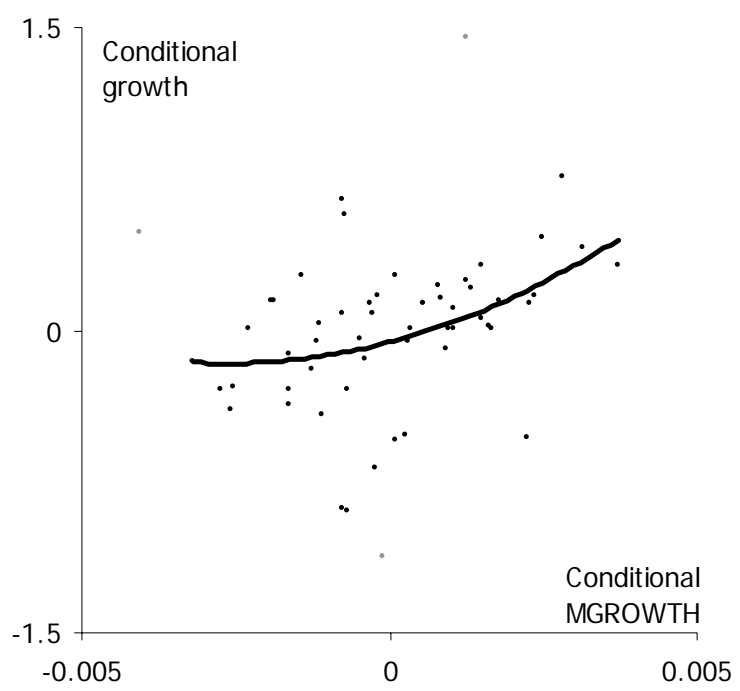

Notes. Vertical axis: DY, conditional on the four MRW variables and three regional dummies. Horizontal axis: MGROWTH, conditional on the same seven variables. Sample: 56 developing countries. Second-order polynomial trend line added, ignoring three strong outliers (if included, they strengthen the evidence of convexity).

Figure 2

Quantile regression estimates for the structural change terms
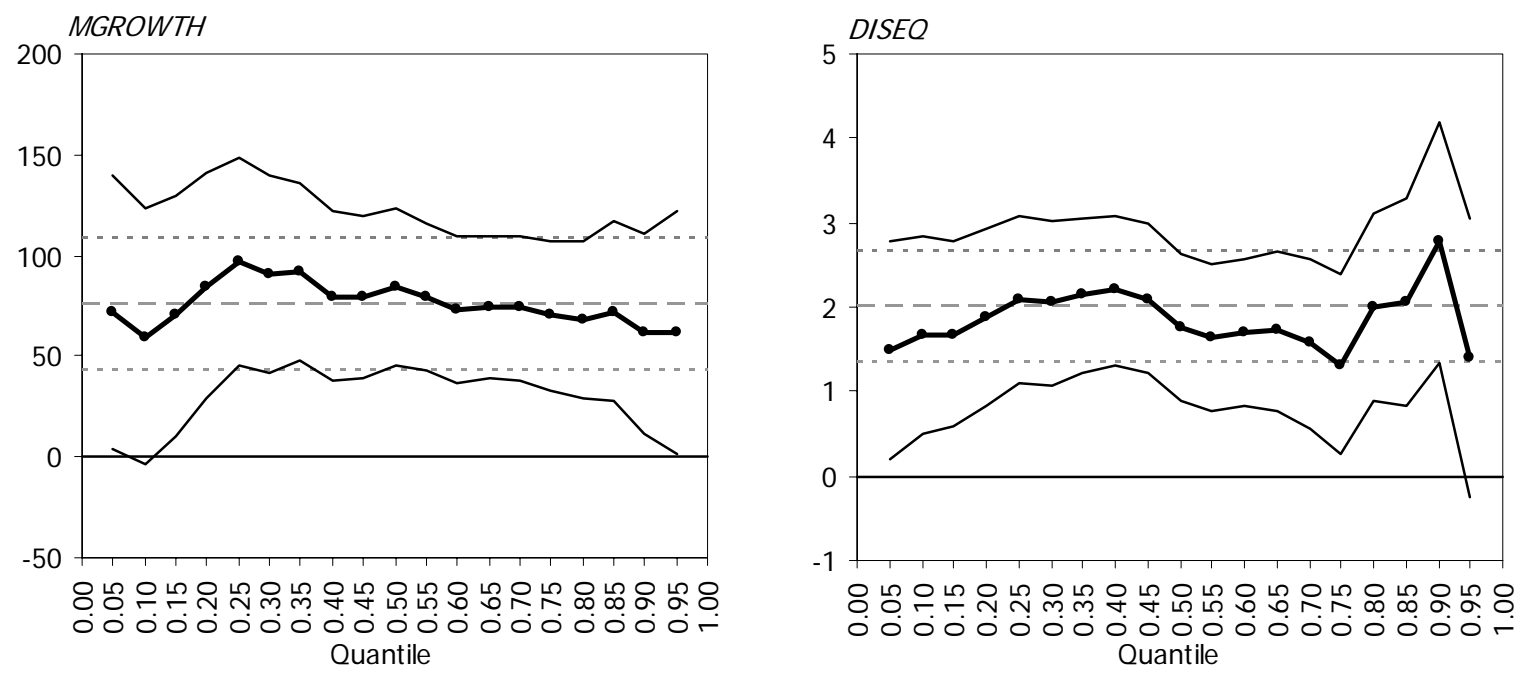

Notes. The underlying models correspond to regressions (14) and (15) of Table 5, respectively. The solid curve with dots represents the coefficient estimates for each quantile, and the two thin solid lines represent the 90 percent confidence bands for these estimates. The long-dashed gray line represents the OLS estimate, with its 90 percent confidence interval represented by the two short-dashed gray lines. 
Appendix

Table A1

Structural change effects in the MRW model, 1960-96: median and robust regression results

\begin{tabular}{|c|c|c|c|c|c|c|c|c|c|}
\hline & (A1) & (A2) & (A3) & (A4) & (A5) & (A6) & (A7) & (A8) & (A9) \\
\hline Regr. technique & MR & MR & MR & MR & MR & MR & $\mathrm{RR}$ & $\mathrm{RR}$ & $\mathrm{RR}$ \\
\hline Observations & 76 & 76 & 76 & 66 & 66 & 66 & 76 & 66 & 65 \\
\hline \multirow[t]{2}{*}{$\ln ($ Investment $)$} & $0.14^{\circ}$ & $0.23^{*}$ & $0.19^{\circ}$ & $0.33^{\circ}$ & $0.40^{*}$ & 0.21 & 0.12 & 0.15 & $0.18^{\circ}$ \\
\hline & $(0.08)$ & (0.09) & $(0.11)$ & $(0.19)$ & $(0.14)$ & $(0.13)$ & $(0.08)$ & $(0.09)$ & (0.09) \\
\hline \multirow[t]{2}{*}{$\ln (Y R S C H)$} & $0.42^{*}$ & $0.36^{*}$ & $0.36^{*}$ & 0.30 & $0.30^{+}$ & $0.36^{+}$ & $0.39^{*}$ & $0.36^{*}$ & $0.41^{*}$ \\
\hline & $(0.08)$ & (0.09) & $(0.10)$ & $(0.19)$ & $(0.14)$ & $(0.14)$ & $(0.09)$ & $(0.10)$ & $(0.10)$ \\
\hline \multirow[t]{2}{*}{$\ln (n+g+\delta)$} & $-0.78^{+}$ & $-1.12^{*}$ & -0.74 & -0.94 & -0.95 & $-0.84^{\circ}$ & $-0.79^{+}$ & -0.50 & $-0.78^{\circ}$ \\
\hline & $(0.35)$ & $(0.36)$ & $(0.47)$ & (0.69) & $(0.61)$ & $(0.48)$ & $(0.36)$ & $(0.41)$ & $(0.41)$ \\
\hline \multirow[t]{2}{*}{$\ln (G D P 60)$} & $-0.38^{*}$ & $-0.35^{*}$ & $-0.34^{*}$ & $-0.35^{*}$ & $-0.32^{*}$ & $-0.38^{*}$ & $-0.38^{*}$ & $-0.37^{*}$ & $-0.35^{*}$ \\
\hline & $(0.06)$ & $(0.07)$ & $(0.08)$ & $(0.13)$ & $(0.11)$ & $(0.09)$ & $(0.07)$ & $(0.07)$ & $(0.07)$ \\
\hline \multirow[t]{2}{*}{ MGROWTH } & 25.62 & $84.32^{*}$ & & & & & 16.60 & & \\
\hline & $(30.56)$ & (17.79) & & & & & $(33.45)$ & & \\
\hline \multirow[t]{2}{*}{ DISEQ } & $1.24^{\circ}$ & & $1.77^{*}$ & & & & $1.53^{+}$ & & \\
\hline & $(0.71)$ & & $(0.47)$ & & & & $(0.76)$ & & \\
\hline \multirow[t]{2}{*}{ MGROWTH2 } & & & & 67.56 & $145.64^{+}$ & & & -1.23 & 77.07 \\
\hline & & & & (121.73) & $(57.04)$ & & & $(65.82)$ & (73.23) \\
\hline \multirow[t]{2}{*}{ DISEQ2 } & & & & 2.52 & & $4.04^{*}$ & & $3.58^{+}$ & 2.35 \\
\hline & & & & (3.04) & & $(1.25)$ & & (1.61) & $(1.75)$ \\
\hline \multirow[t]{2}{*}{ Constant } & 1.77 & 0.62 & 1.71 & 1.37 & 1.13 & 1.64 & 1.65 & $2.49^{+}$ & 1.43 \\
\hline & $(1.07)$ & $(1.13)$ & $(1.42)$ & $(2.23)$ & $(1.86)$ & $(1.49)$ & $(1.12)$ & $(1.20)$ & $(1.22)$ \\
\hline$R^{2}$ & 0.53 & 0.51 & 0.52 & 0.55 & 0.54 & 0.55 & & & \\
\hline$F$ (struct. change) & 11.50 & & & 2.80 & & & 11.80 & 7.63 & 10.01 \\
\hline Prob. $>F$ & 0.0001 & & & 0.0694 & & & 0.0000 & 0.0012 & 0.0002 \\
\hline
\end{tabular}

Notes. Dependent variable: log difference of GDP per worker, 1960-96. All regressions control for regional dummies; coefficients on regional dummies not reported. White heteroscedasticity-consistent standard errors in parentheses. DISEQ and DISEQ2 re-scaled by multiplying by 1000. Regression (A9) excludes Singapore. Significance level: * $1 \%$; ${ }^{+} 5 \%$; ${ }^{\circ} 10 \%$. 
Table A2

Structural change effects in developing countries, 1960-96

\begin{tabular}{|c|c|c|c|c|c|c|c|}
\hline & (A10) & (A11) & (A12) & (A13) & (A14) & (A15) & (A16) \\
\hline Regression technique & OLS & OLS & OLS & OLS & MR & MR & MR \\
\hline Observations & 48 & 48 & 48 & 56 & 56 & 56 & 56 \\
\hline \multirow[t]{2}{*}{$\ln ($ Investment $)$} & 0.36 & $0.42^{\circ}$ & 0.34 & 0.27 & 0.25 & 0.26 & 0.21 \\
\hline & $(0.23)$ & $(0.24)$ & $(0.21)$ & $(0.17)$ & $(0.18)$ & $(0.16)$ & $(0.10)$ \\
\hline \multirow[t]{2}{*}{$\ln (Y R S C H)$} & $0.37^{+}$ & $0.39^{+}$ & $0.37^{*}$ & $0.32^{*}$ & $0.32^{\circ}$ & $0.37^{+}$ & $0.35^{*}$ \\
\hline & $(0.14)$ & $(0.15)$ & $(0.13)$ & $(0.12)$ & $(0.17)$ & $(0.16)$ & $(0.09)$ \\
\hline \multirow[t]{2}{*}{$\ln (n+g+\delta)$} & $-1.40^{\circ}$ & -1.20 & $-1.46^{\circ}$ & -1.07 & -1.19 & -1.29 & $-0.87^{\circ}$ \\
\hline & $(0.74)$ & $(0.77)$ & $(0.75)$ & $(0.67)$ & $(0.89)$ & $(0.84)$ & $(0.49)$ \\
\hline \multirow[t]{2}{*}{$\ln (G D P 60)$} & $-0.36^{*}$ & $-0.27^{+}$ & $-0.38^{*}$ & $-0.50^{*}$ & $-0.34^{+}$ & $-0.34^{+}$ & $-0.35^{*}$ \\
\hline & $(0.13)$ & $(0.12)$ & $(0.12)$ & $(0.13)$ & $(0.14)$ & $(0.13)$ & $(0.08)$ \\
\hline \multirow[t]{2}{*}{ MGROWTH } & & & & -43.92 & 25.72 & $94.20^{+}$ & \\
\hline & & & & $(52.49)$ & $(72.37)$ & $(39.33)$ & \\
\hline \multirow[t]{2}{*}{ DISEQ } & & & & $2.58^{+}$ & 1.70 & & $2.28^{*}$ \\
\hline & & & & $(1.21)$ & $(1.80)$ & & $(0.62)$ \\
\hline \multirow[t]{2}{*}{ MGROWTH2 } & 46.05 & $180.10^{*}$ & & & & & \\
\hline & (98.09) & $(56.01)$ & & & & & \\
\hline \multirow[t]{2}{*}{ DISEQ2 } & 4.42 & & $5.40^{*}$ & & & & \\
\hline & $(3.01)$ & & $(1.77)$ & & & & \\
\hline \multirow[t]{2}{*}{$M G R O W T H *$ SSAfrica } & & & & 53.15 & & & \\
\hline & & & & (185.64) & & & \\
\hline \multirow[t]{2}{*}{ DISEQ $*$ SSAfrica } & & & & 3.91 & & & \\
\hline & & & & $(4.36)$ & & & \\
\hline \multirow[t]{2}{*}{ Constant } & 0.23 & 0.01 & 0.26 & 2.46 & 0.63 & 0.04 & 1.44 \\
\hline & $(1.88)$ & $(1.95)$ & $(1.84)$ & $(2.01)$ & $(2.39)$ & $(2.25)$ & $(1.28)$ \\
\hline$R^{2}$ & 0.69 & 0.68 & 0.69 & 0.70 & 0.49 & 0.48 & 0.49 \\
\hline s.e. & 0.44 & 0.45 & 0.44 & 0.41 & & & \\
\hline$F$ (structural change) & 5.58 & & & 3.69 & 2.17 & & \\
\hline Prob. $>F$ & 0.0075 & & & 0.0113 & 0.1261 & & \\
\hline
\end{tabular}

Notes. Dependent variable: log difference of GDP per worker, 1960-96. All regressions control for regional dummies; coefficients on regional dummies not reported. White heteroscedasticity-consistent standard errors in parentheses. DISEQ and DISEQ2 re-scaled by multiplying by $1000 . R^{2}$ : Pseudo $R^{2}$ in the case of MR. Significance level: ${ }^{*} 1 \% ;{ }^{+} 5 \% ;{ }^{\circ} 10 \%$. 
Table A3

Structural change effects on TFP growth: sub-periods and developing countries

\begin{tabular}{|c|c|c|c|c|c|c|c|c|c|}
\hline & (A17) & (A18) & (A19) & (A20) & (A21) & (A22) & (A23) & (A24) & (A25) \\
\hline TFP series & BG & BG & BG & BG & KR & KR & BG & BG & $\mathrm{BC}$ \\
\hline Period & $1965-80$ & $1965-80$ & $1965-80$ & 1980-95 & 1960-85 & 1960-85 & 1965-95 & 1965-95 & $1960-2000$ \\
\hline Observations & 75 & 75 & 75 & 75 & 55 & 48 & 66 & 41 & 43 \\
\hline \multirow[t]{2}{*}{ MGROWTH } & 34.91 & $125.08^{*}$ & & $-193.39^{+}$ & 47.84 & & $-238.42^{+}$ & & \\
\hline & (99.18) & $(42.63)$ & & $(95.71)$ & $(72.11)$ & & (100.10) & & \\
\hline \multirow[t]{2}{*}{ DISEQ } & 2.19 & & $2.79^{*}$ & $4.67^{+}$ & 2.02 & & $6.56^{*}$ & & \\
\hline & (1.83) & & $(0.74)$ & $(1.84)$ & (1.77) & & $(2.09)$ & & \\
\hline \multirow[t]{2}{*}{ MGROWTH2 } & & & & & & -85.55 & & -240.09 & -94.58 \\
\hline & & & & & & $(84.06)$ & & $(200.70)$ & (135.58) \\
\hline \multirow[t]{2}{*}{ DISEQ2 } & & & & & & $9.50^{*}$ & & $8.60^{\circ}$ & $5.64^{\circ}$ \\
\hline & & & & & & $(3.20)$ & & $(4.78)$ & $(2.89)$ \\
\hline \multirow[t]{2}{*}{$\ln (T F P 60)$} & $-1.62^{*}$ & $-1.51^{*}$ & $-1.65^{*}$ & -0.68 & $-1.29^{*}$ & $-1.50^{*}$ & $-1.23^{*}$ & $-1.31^{\circ}$ & \\
\hline & $(0.43)$ & $(0.42)$ & $(0.42)$ & $(0.57)$ & $(0.44)$ & $(0.39)$ & $(0.44)$ & $(0.60)$ & \\
\hline \multirow[t]{2}{*}{ Constant } & $-1.56^{*}$ & $-1.64^{*}$ & $-1.47^{*}$ & 0.60 & -0.19 & -0.17 & 0.25 & -0.18 & $1.00^{*}$ \\
\hline & $(0.55)$ & $(0.54)$ & $(0.51)$ & $(0.75)$ & $(0.33)$ & $(0.28)$ & $(0.39)$ & $(0.57)$ & $(0.28)$ \\
\hline$R^{2}$ & 0.40 & 0.38 & 0.40 & 0.37 & 0.44 & 0.48 & 0.51 & 0.37 & 0.32 \\
\hline s.e. & 1.12 & 1.13 & 1.12 & 1.26 & 0.53 & 0.51 & 0.93 & 1.18 & 0.66 \\
\hline$F$ (stru. change) & 7.40 & & & 3.23 & 6.98 & 5.34 & 4.94 & 1.64 & 2.03 \\
\hline Prob. $>F$ & 0.0013 & & & 0.0457 & 0.0022 & 0.0087 & 0.0104 & 0.2091 & 0.1452 \\
\hline
\end{tabular}

Notes. Dependent variable: Average annual growth rate of total factor productivity, in percent. All regressions control for regional dummies; coefficients on regional dummies not reported. White heteroscedasticity-consistent standard errors in parentheses. DISEQ and DISEQ2 re-scaled by multiplying by 1000. TFP series: KR $=$ Klenow and Rodriguez-Clare (1997); BG = Bernanke and Gürkaynak (2001); BC = Bosworth and Collins (2003). Significance level: ${ }^{*} 1 \% ;{ }^{+} 5 \% ;{ }^{\circ} 10 \%$. 


\section{Table A4}

\section{NLS regressions}

\begin{tabular}{|c|c|c|c|c|}
\hline \multirow{2}{*}{$\begin{array}{l}\text { Dependent variable } \\
\text { Sample }\end{array}$} & \multicolumn{2}{|c|}{ Growth } & \multicolumn{2}{|c|}{ TFP-KR } \\
\hline & all & developing & all & developing \\
\hline \multicolumn{5}{|c|}{ Restricted model with $\psi=\infty$} \\
\hline & (A26) & (A27) & (A28) & (A29) \\
\hline \multirow[t]{2}{*}{$k$} & $2.54^{*}$ & $2.38^{+}$ & $4.63^{*}$ & $4.55^{+}$ \\
\hline & $(0.81)$ & $(0.96)$ & $(1.58)$ & $(1.84)$ \\
\hline \multicolumn{5}{|c|}{ Restricted model wit $k=1$} \\
\hline & (A30) & (A31) & (A32) & (A33) \\
\hline \multirow[t]{2}{*}{$\psi$} & $0.0160^{+}$ & $0.0153^{\circ}$ & $0.0044^{+}$ & $0.0041^{+}$ \\
\hline & $(0.0074)$ & $(0.0089)$ & $(0.0017)$ & $(0.0018)$ \\
\hline \multicolumn{5}{|l|}{$w_{m} / w_{a}$} \\
\hline $10^{\text {th }}$ percentile & 1.21 & 1.20 & 1.76 & 1.75 \\
\hline median & 2.27 & 1.81 & 5.56 & 4.21 \\
\hline $90^{\text {th }}$ percentile & 3.72 & 3.30 & 10.77 & 9.53 \\
\hline
\end{tabular}

Notes. Dependent variable: average annual growth of GDP per worker, 1960-96, in case of the growth regressions; average annual growth rate of total factor productivity, 1960-85, in case of the TFP regressions. All regressions control for regional dummies. The growth regressions additionally control for the four MRW variables (investment, schooling, $\ln (n+g+\delta)$, and initial GDP). The TFP regressions additionally control for the log of initial TFP. Coefficients on control variables not reported. Significance level: ${ }^{*} 1 \% ;{ }^{+} 5 \% ;{ }^{\circ} 10 \%$ 